ArgOn national laboratory

\title{
On a Thermal Analysis of a Second Stripper for Rare Isotope Accelerator
}

Nuclear Engineering and Physics Divisions 


\begin{abstract}
About Argonne National Laboratory
Argonne is a U.S. Department of Energy laboratory managed by UChicago Argonne, LLC under contract DE-AC02-06CH11357. The Laboratory's main facility is outside Chicago, at 9700 South Cass Avenue, Argonne, Illinois 60439. For information about Argonne, see www.anl.gov.
\end{abstract}

\title{
Availability of This Report
}

This report is available, at no cost, at http://www.osti.gov/bridge. It is also available on paper to the U.S. Department of Energy and its contractors, for a processing fee, from:

U.S. Department of Energy

Office of Scientific and Technical Information

P.O. Box 62

Oak Ridge, TN 37831-0062

phone (865) 576-8401

fax (865) 576-5728

reports@adonis.osti.gov

\begin{abstract}
Disclaimer
This report was prepared as an account of work sponsored by an agency of the United States Government. Neither the United States Government nor any agency thereof, nor UChicago Argonne, LLC, nor any of their employees or officers, makes any warranty, express or implied, or assumes any legal liability or responsibility for the accuracy, completeness, or usefulness of any information, apparatus, product, or process disclosed, or represents that its use would not infringe privately owned rights. Reference herein to any specific commercial product, process, or service by trade name, trademark, manufacturer, or otherwise, does not necessarily constitute or imply its endorsement, recommendation, or favoring by the United States Government or any agency thereof. The views and opinions of document authors expressed herein do not necessarily state or reflect those of the United States Government or any agency thereof, Argonne National Laboratory, or UChicago Argonne, LLC.
\end{abstract}




\section{On a Thermal Analysis of a Second Stripper for Rare Isotope Accelerator}

Yoichi Momozaki, Nuclear Engineering Division and Jerry Nolen, Physics Division Argonne National Laboratory

July 2008 


\section{Table of contents}

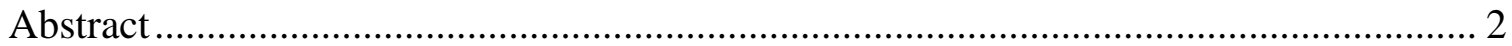

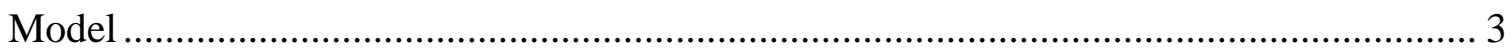

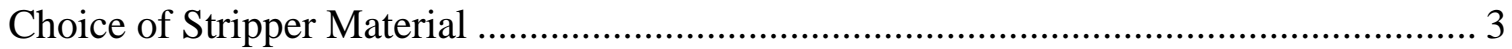

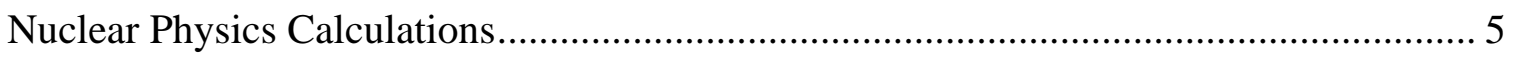

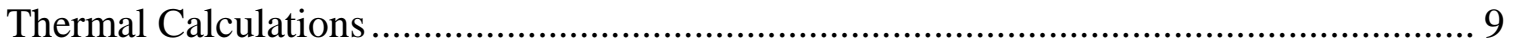

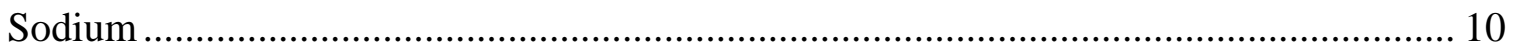

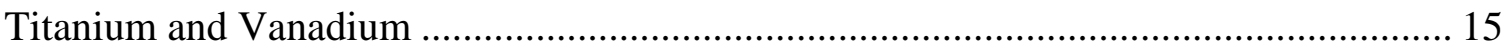

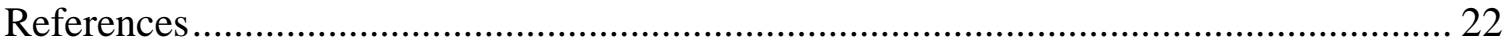

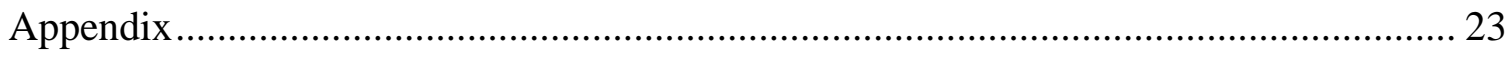




\title{
On a Thermal Analysis of a Second Stripper for RIA Yoichi Momozaki and Jerry Nolen
}

\begin{abstract}
This memo summarizes simple calculations and results of the thermal analysis on the second stripper to be used in the driver linac of Rare Isotope Accelerator (RIA). Both liquid (Sodium) and solid (Titanium and Vanadium) stripper concepts were considered. These calculations were intended to provide basic information to evaluate the feasibility of liquid (thick film) and solid (rotating wheel) second strippers. Nuclear physics calculations to estimate the volumetric heat generation in the stripper material were performed by "LISE for Excel". In the thermal calculations, the strippers were modeled as a thin 2D plate with uniform heat generation within the beam spot. Then, temperature distributions were computed by assuming that the heat spreads conductively in the plate in radial direction without radiative heat losses to surroundings.
\end{abstract}




\section{Model}

A schematic of the second stripper is shown in Figure 1. The stripper was modeled as a moving slab at velocity $v$, which could be a liquid or a solid. An incident $U$ beam at the charge state of $72+$, flux of 4 particle $\mu \mathrm{A}$, and energy of $85 \mathrm{MeV} /$ nucleon passes through the stripper material and deposits some energy as heat within the stripper. Expected beam diameter was $1 \mathrm{~mm}$.

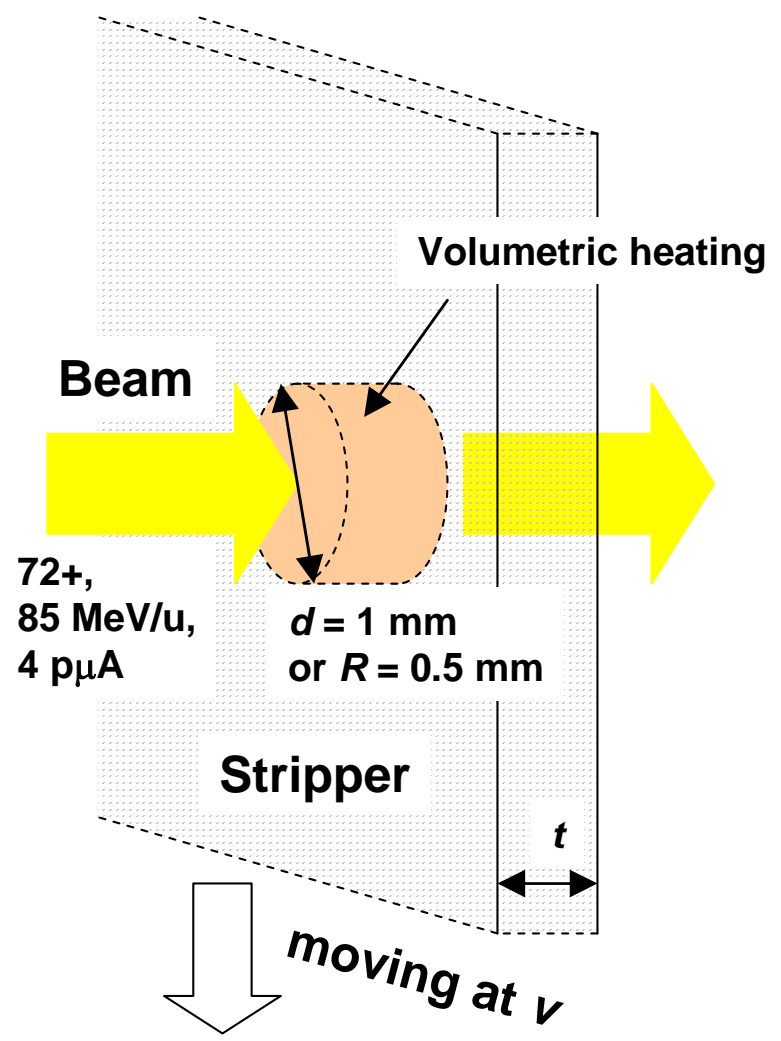

Figure 1. Schematic of Second Stripper.

\section{Choice of Stripper Material}

To experimentally determine the best stripper material at around $80 \mathrm{MeV} / \mathrm{u}$, the series of experiments to determine the charge state distribution as a function of material variation and thickness was performed at National Superconducting Cyclotron Laboratory (NSCL) in Michigan State University (MSU). To simulate a $80 \mathrm{MeV} / \mathrm{u}$, U beam, $\mathrm{Bi}$ beam at $80 \mathrm{MeV} / \mathrm{u}$ and the charge state of 63+ was used in the experiments. Various stripper materials with different dimensions including Be $13.2 \mathrm{mg} / \mathrm{cm}^{2}$, C 16.8 $\mathrm{mg} / \mathrm{cm}^{2}$, Al $10.8 \mathrm{mg} / \mathrm{cm}^{2}$, Al $15.5 \mathrm{mg} / \mathrm{cm}^{2}$, V $14.0 \mathrm{mg} / \mathrm{cm}^{2}$, Cu $8.4 \mathrm{mg} / \mathrm{cm}^{2}$, and $\mathrm{Cu} 17.9$ $\mathrm{mg} / \mathrm{cm}^{2}$ were tested. Results are summarized in Table 1, Figure 2, and Figure 3. 
Table 1. Summary of Charge Distribution.

\begin{tabular}{|c|c|c|c|c|c|c|c|c|}
\hline \multirow[t]{11}{*}{ Q } & & $\begin{array}{l}\text { Be } 13.2 \mathrm{mg} / \mathrm{cm}^{2} \\
\text { fractions }\end{array}$ & $\begin{array}{l}\text { C } 16.8 \mathrm{mg} / \mathrm{cm}^{2} \\
\text { fractions }\end{array}$ & $\begin{array}{l}\text { Al } 10.8 \mathrm{mg} / \mathrm{cm}^{2} \\
\text { fractions }\end{array}$ & $\begin{array}{l}\text { Al } 15.5 \mathrm{mg} / \mathrm{cm}^{2} \\
\text { fractions }\end{array}$ & $\begin{array}{l}V 14.0 \mathrm{mg} / \mathrm{cm}^{2} \\
\text { fractions }\end{array}$ & $\begin{array}{l}\mathrm{Cu} 8.4 \mathrm{mg} / \mathrm{cm}^{2} \\
\text { fractions }\end{array}$ & $\begin{array}{l}\text { Cu } 17.9 \mathrm{mg} / \mathrm{cm}^{2} \\
\text { fractions }\end{array}$ \\
\hline & 83 & & 0.000166432 & 0.000138825 & 0.000291122 & 4.07711E-05 & $3.55096 \mathrm{E}-05$ & 4.19519E-05 \\
\hline & 82 & 0.000781956 & 0.016127091 & 0.011693697 & 0.012104976 & 0.002219475 & 0.001717779 & 0.001384412 \\
\hline & 81 & 0.050323568 & 0.390985875 & 0.259024419 & 0.255559266 & 0.078203996 & 0.059727247 & 0.051983045 \\
\hline & 80 & 0.193424653 & 0.397093588 & 0.37251853 & 0.3709073 & 0.231629331 & 0.200163425 & 0.185592045 \\
\hline & 79 & 0.311737494 & 0.153659036 & 0.24092467 & 0.241536573 & 0.306225504 & 0.294056822 & 0.289109949 \\
\hline & 78 & 0.272114096 & 0.036574167 & 0.089083214 & 0.092108926 & 0.2281583 & 0.252602564 & 0.259436984 \\
\hline & 77 & 0.13419233 & 0.004958026 & 0.022542115 & 0.022964242 & 0.109213508 & 0.132073138 & 0.146067652 \\
\hline & 76 & 0.037425903 & 0.000435785 & 0.003647416 & 0.004080031 & 0.035111513 & 0.045862265 & 0.054109523 \\
\hline & 75 & & & 0.000420334 & 0.000447565 & 0.00792882 & 0.011896409 & 0.012274438 \\
\hline & 74 & & & 6.77958E-06 & & 0.001268782 & 0.001864843 & \\
\hline \multirow{2}{*}{\multicolumn{2}{|c|}{$\begin{array}{l}\text { centroid } \\
\text { Atomic number }\end{array}$}} & 78.64364119 & 80.18031477 & 79.77937883 & 79.76743748 & 78.80487979 & 78.61366781 & 78.53088057 \\
\hline & & 4 & 6 & 13 & 13 & 23 & 29 & 29 \\
\hline
\end{tabular}

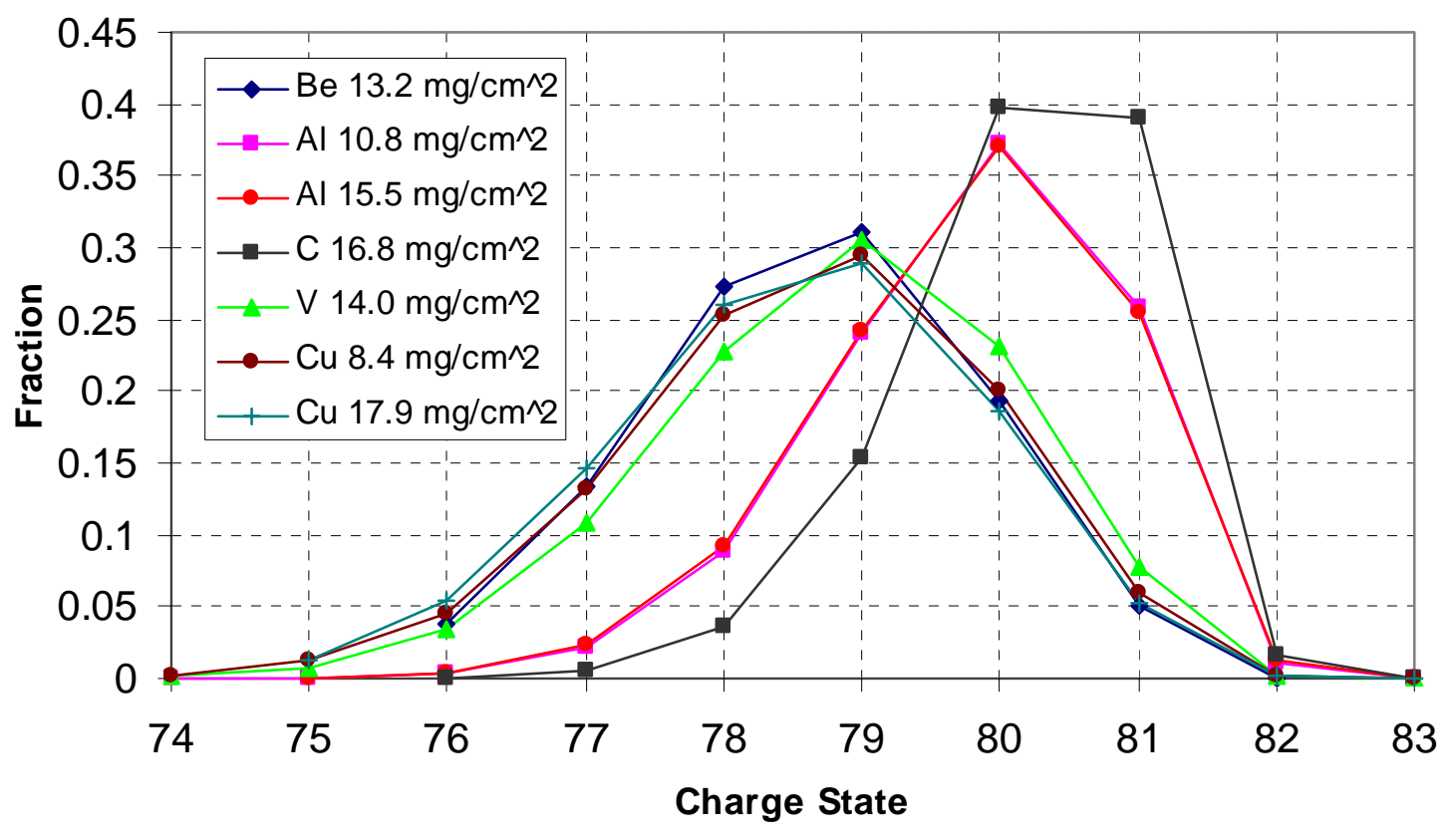

Figure 2. Charge Distribution for Various Materials with different thicknesses (for Al and Cu).

From these results, it appeared that a material with the atomic number ranging from 6 to 23 would possess good stripping characteristics (Figure 3). However, since carbon does not retain the good dimensional uniformity, it was not selected as a candidate for the stripper material. Other metallic materials, including $\mathrm{Mg}, \mathrm{Al}, \mathrm{Ca}$, and $\mathrm{Sc}$, are either chemically not very stable, having low melting point, or not readily available, and were not considered suitable candidates. These considerations left $\mathrm{Na}$ as a candidate for the liquid stripper and $\mathrm{Ti}$ and $\mathrm{V}$ as candidates for the solid stripper.

Also, the obtained charge distributions for $\mathrm{Al} 10.8 \mathrm{mg} / \mathrm{cm}^{2}$ and $15.5 \mathrm{mg} / \mathrm{cm}^{2}$ were almost identical and those for $\mathrm{Cu} 8.4 \mathrm{mg} / \mathrm{cm}^{2}$ and $17.9 \mathrm{mg} / \mathrm{cm}^{2}$ were very similar (Figure 2 ), indicating that the minimum thickness to reach equilibrium charge state distribution would have been approximately $10 \mathrm{mg} / \mathrm{cm}^{2}$ for the present case. 


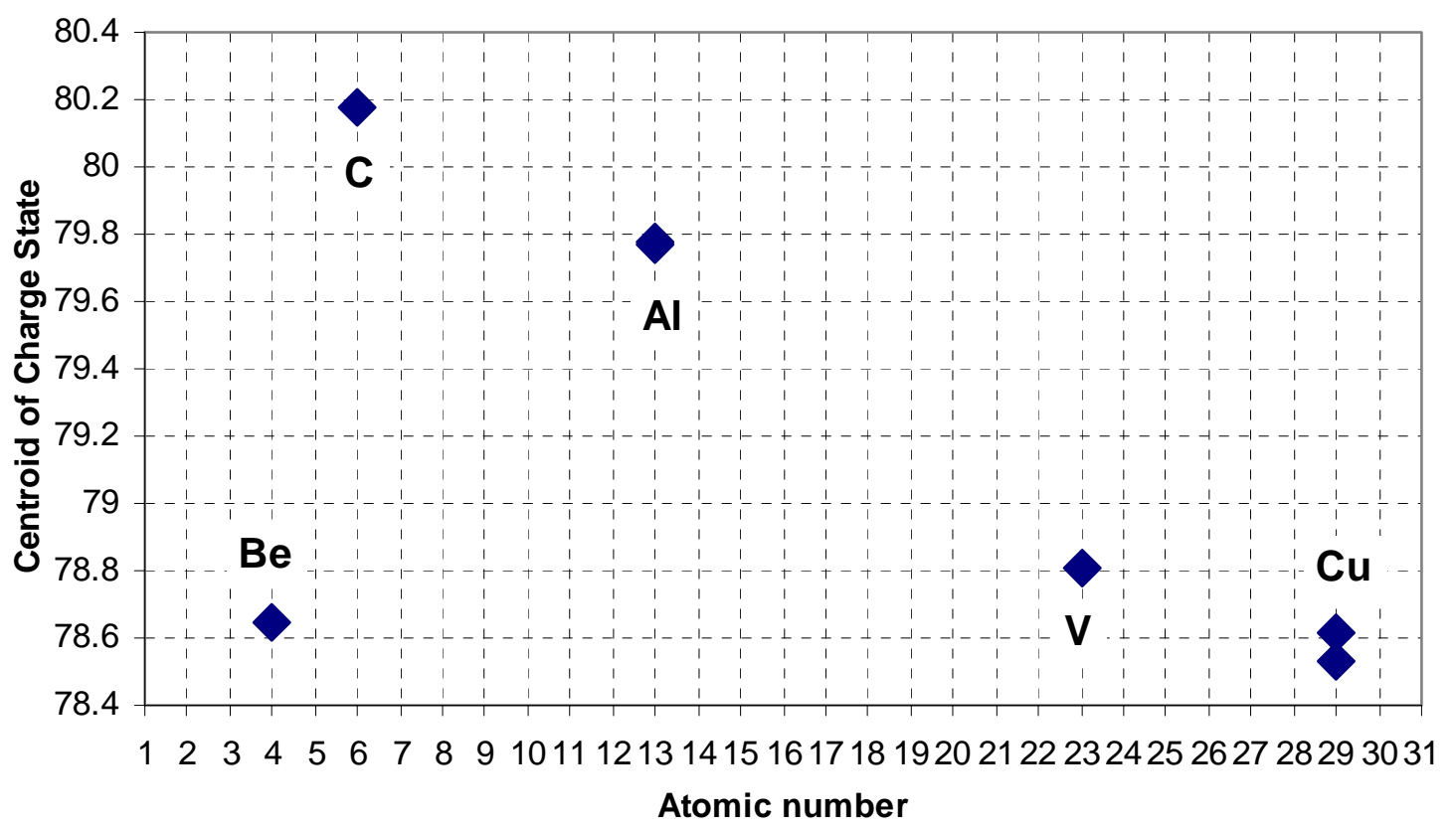

Figure 3. Change in Centroid of Charge Distribution as a Function of Atomic Number.

\section{Nuclear Physics Calculations}

To evaluate the volumetric heat generation in the stripper material, the function "EnergyLossInMatter_option( $\left.Z \_p, A \_p, E, Z_{-} t, \Delta t, O P T\right)$ )" in LISE for Excel was used. This function requires 6 arguments; $Z \_p$ is the atomic number of an incident beam, $A \_p$ is the atomic mass number of an incident beam, $E$ is the energy of an incident beam in $\mathrm{MeV} /$ nucleon, $Z_{-} t$ is the atomic number of a target material, $\Delta t$ is the thickness of a target in $\mathrm{mg} / \mathrm{cm}^{2}$, and $O P T$ is a flag to specify which model is used in the calculation (i.e. $0=$ Hubert, $1=$ Ziegler, $2=$ ATIMA). $O P T=2$ was used in this study. The thickness, $\Delta t$, is related to the actual physical distance $\Delta x$ in meters as,

$$
\Delta t=100 \rho \Delta x,
$$

where $\rho$ is the density of the target in $\mathrm{kg} / \mathrm{m}^{3}$. The function, "EnergyLossInMatter_option" returns the value of the incident beam energy after penetrating through the target with a thickness of $\Delta t$ specified in the arguments shown in Figure 4.

Then, the volumetric heat generation, $Q$ '", in the stripper was calculated as,

$$
Q^{\prime \prime \prime}(x)=\frac{Q^{\prime \prime}}{E(0)} \frac{E(x-\Delta x)-E(x+\Delta x)}{2 \Delta x},
$$

where $Q^{\prime \prime}$ is the initial energy flux density of the incident beam. The initial energy flux density, $Q^{\prime \prime}$ in $\mathrm{W} / \mathrm{m}^{2}$ was calculated as, 


$$
Q^{\prime \prime}=\frac{E(0) \times A_{-} p \times i_{B}}{\pi R^{2}},
$$

where $E(0)$ is the energy of an incident beam in $\mathrm{MeV} /$ nucleon, $i_{B}$ is the beam flux in particle $\mu \mathrm{A}$, and $R$ is the radius of the beam spot in meter. For the case of the incident $\mathrm{U}$ beam at the flux of 4 particle $\mu \mathrm{A}$ and energy of $85 \mathrm{MeV} /$ nucleon, the initial energy flux is $80920 \mathrm{~W}(\sim 81 \mathrm{~kW})$ and the energy flux density is $Q^{\prime \prime}=1.03 \times 10^{11} \mathrm{~W} / \mathrm{m}^{2}$. Several results are presented in the following figures.

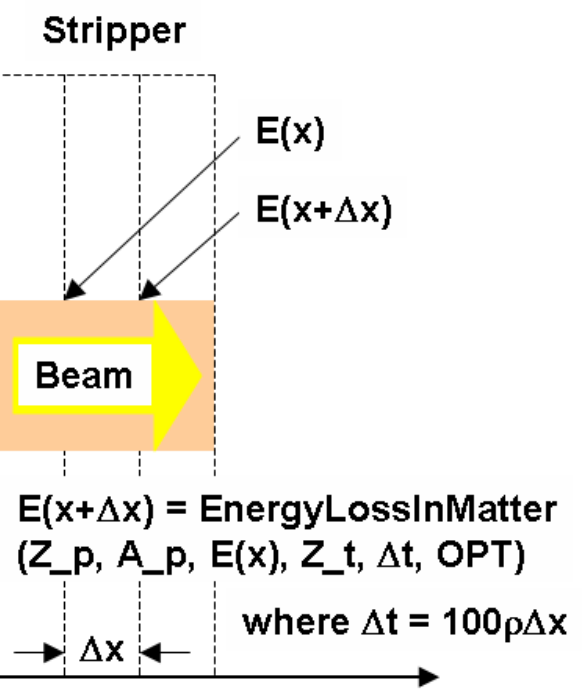

Figure 4. Calculating Energy Loss in the Target.

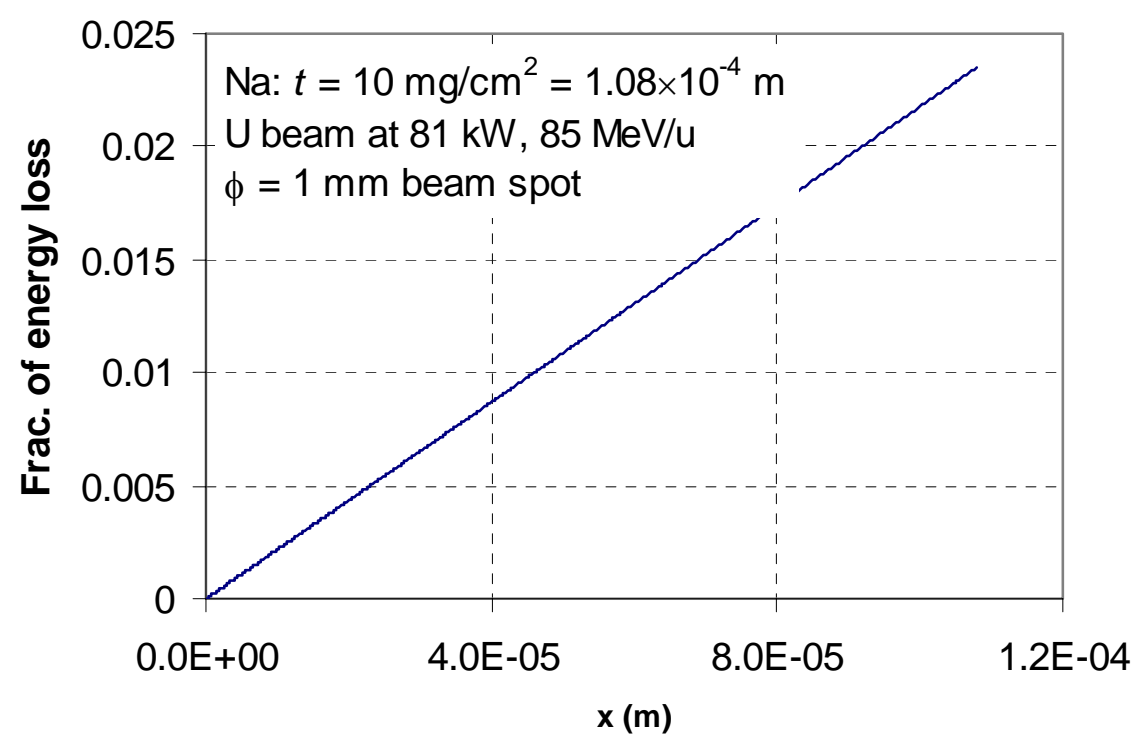

Figure 5. Beam Energy Loss Profile in the Na $2^{\text {nd }}$ Stripper. 


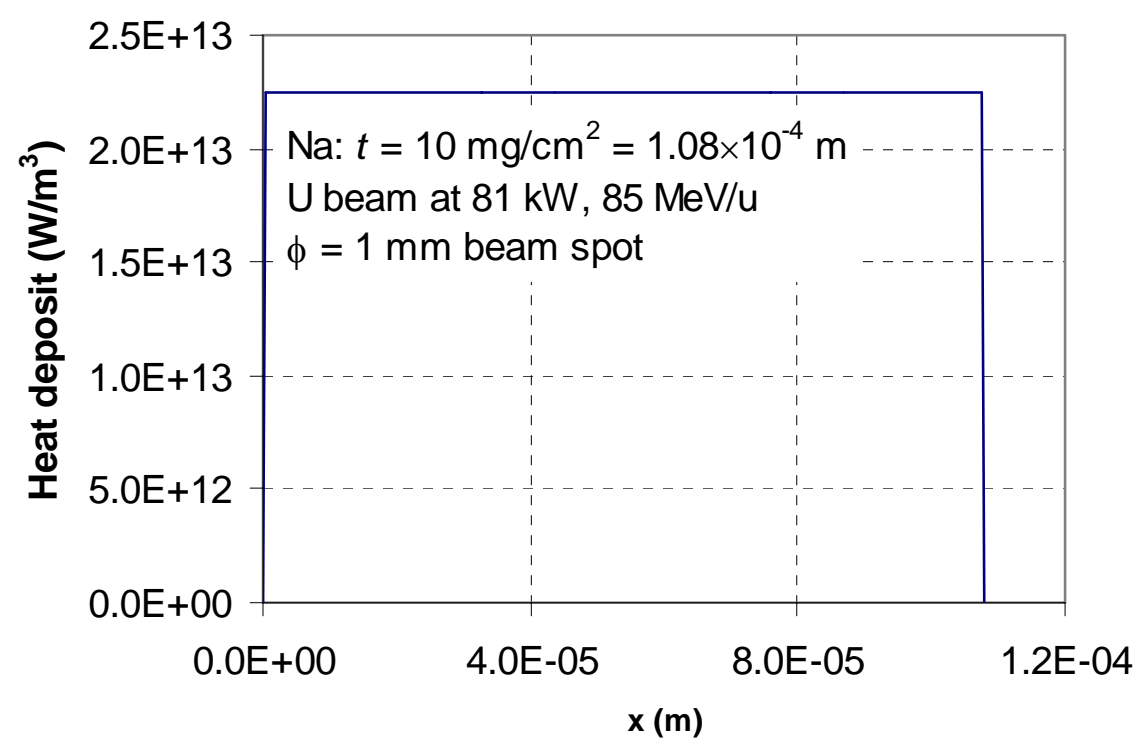

Figure 6. Volumetric Heat Generation in the Na $2^{\text {nd }}$ Stripper.

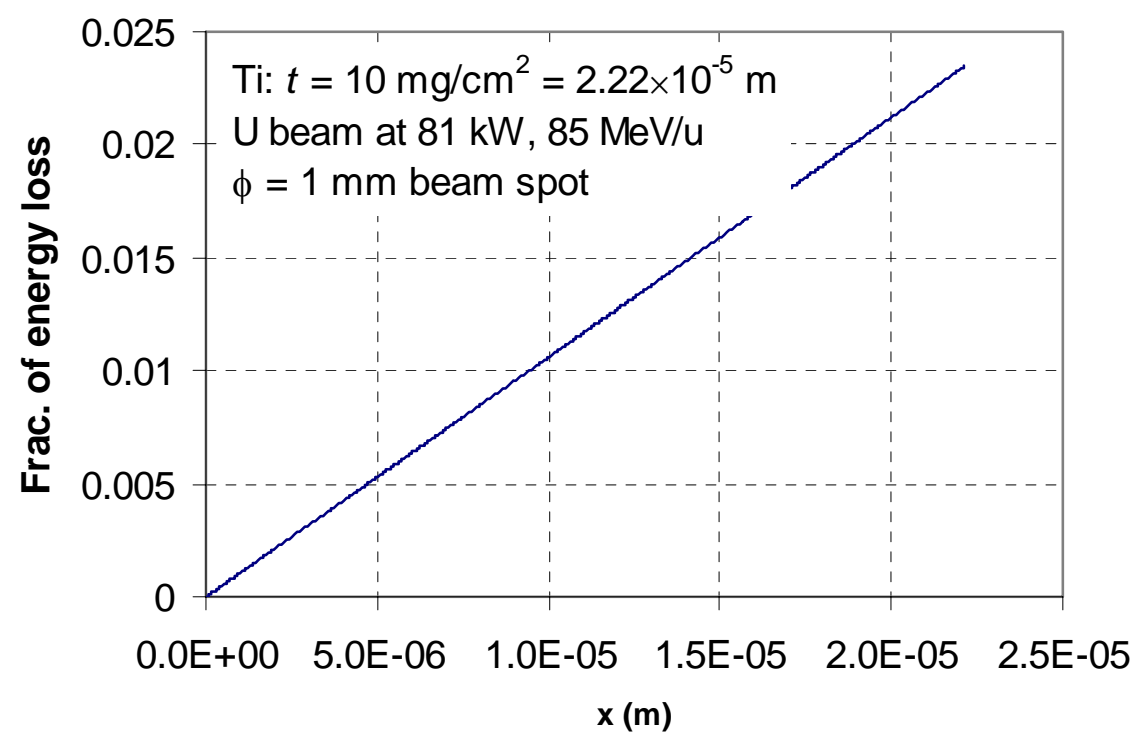

Figure 7. Beam Energy Loss Profile in the Ti $2^{\text {nd }}$ Stripper. 


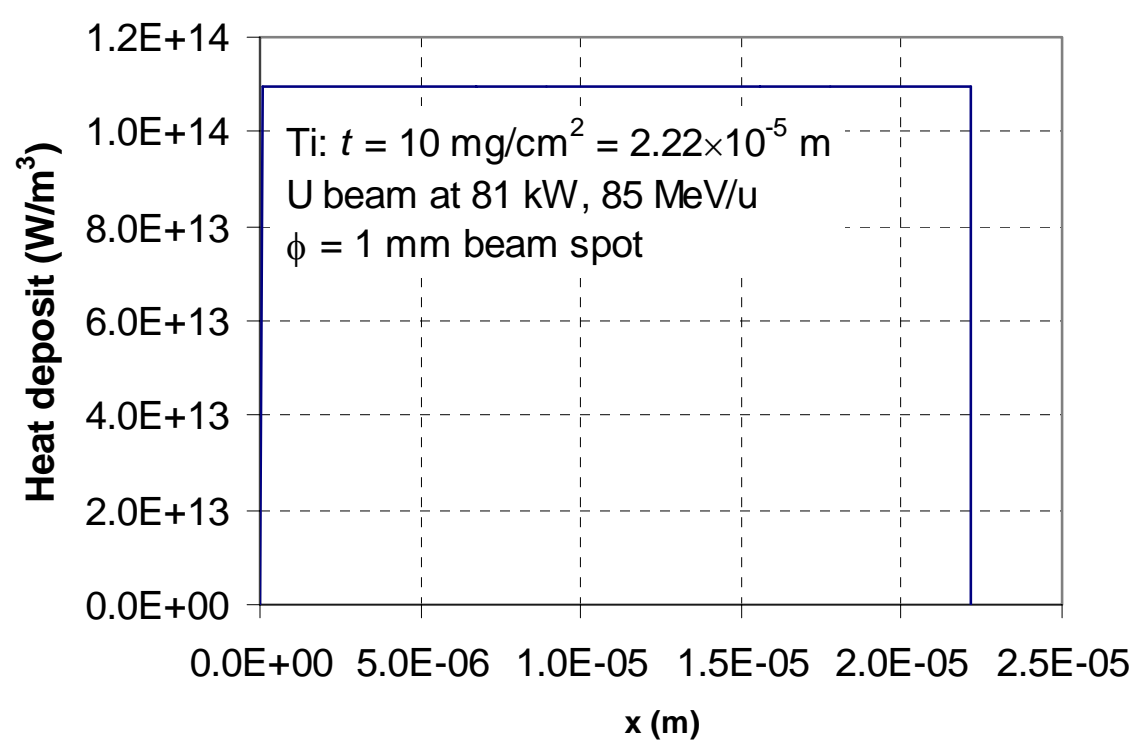

Figure 8. Volumetric Heat Generation in the Ti $2^{\text {nd }}$ Stripper.

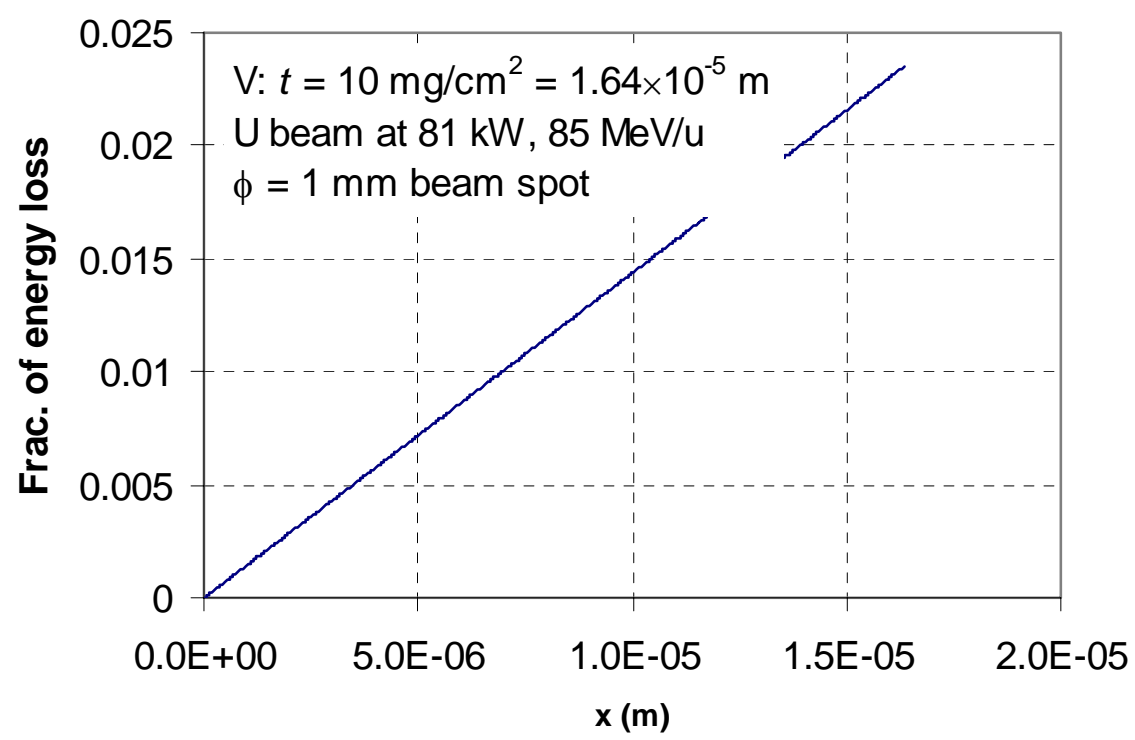

Figure 9. Beam Energy Loss Profile in the V $2^{\text {nd }}$ Stripper. 


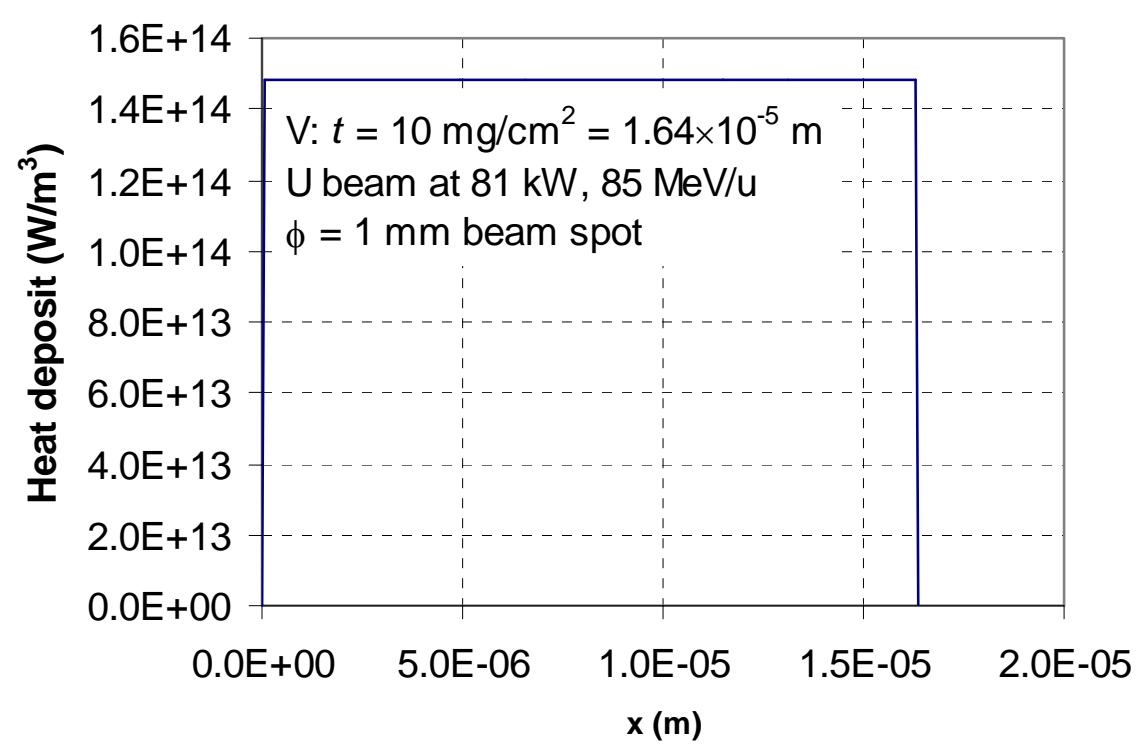

Figure 10. Volumetric Heat Generation in the $\mathrm{V} 2^{\text {nd }}$ Stripper.

These figures suggest that this problem may be treated as a 2-D problem since the profile of the volumetric heat generation in the stripper material is uniform across the thickness of the material and the material is very thin. The fraction of the energy loss in the stripper materials at $10 \mathrm{mg} / \mathrm{cm}^{2}$ thickness for a $\mathrm{U}$ beam at $85 \mathrm{MeV} / \mathrm{u}$ and $81 \mathrm{~kW}$ over a spot diameter of $1 \mathrm{~mm}$ is 0.0235 for all cases and corresponding energy loss, $Q$ is 1900 W.

\section{Thermal Calculations}

Introducing some simplifications into this problem made it possible to use an analytical solution for a heat conduction problem of a moving, solid body. Since the stripper is very thin, the problem may be treated as a 2-D problem (Pittaway, 1964). In this analysis, a heat source that had Gaussian distribution was moving at the velocity, $v$ $\mathrm{m} / \mathrm{s}$ on a thin stripper material. The stripper had a constant, uniform, background temperature of $T_{\infty}$. For simplicity, it was assumed that no heat transfer from the surfaces of the stripper took place. Then, the temperature distribution in the thin stripper material is given as (Pittaway, 1964),

$$
T(a, b, m)=T_{\infty}+\frac{a^{2} Q}{4 \pi k t} \int_{0}^{\infty} \frac{1}{1+a^{2} z} \exp \left[-\frac{(a z+m)^{2}+b^{2}}{1+a^{2} z}\right] d z,
$$

where $a=\frac{4 k}{\rho C_{p} v R}, b=\frac{y}{R}, m=\frac{x}{R}$. In this coordinate, the origin $(x=0, y=0)$ is the center of the beam spot. 
The integration in Eq. (4) was numerically performed using a Fortran code that implemented Romberg's method (Press et. al., 1992). Source codes and input file are attached in Appendix. Several results are presented in the following figures.

\section{Sodium}

The initial background temperature for $\mathrm{Na}$ was taken to be $381 \mathrm{~K}$ that is $10 \mathrm{~K}$ above the melting point of $\mathrm{Na}$. Results of the thermal calculations while changing the $\mathrm{Na}$ film velocity from $10 \mathrm{~m} / \mathrm{s}$ to $100 \mathrm{~m} / \mathrm{s}$ are presented in Figures 11-16. Figures 11-13 present the spatial temperature distribution of the $\mathrm{Na}$ film along the beam line. Figures 14-16 show the 2D spatial temperature distribution of the film near the beam spot. These figures show that for a once-through $\mathrm{Na}$ stripper system, the calculated maximum temperatures of the Na film are $\sim 1800 \mathrm{~K}, \sim 680 \mathrm{~K}$, and $\sim 530 \mathrm{~K}$ for Na film velocity of 10 $\mathrm{m} / \mathrm{s}, 50 \mathrm{~m} / \mathrm{s}$, and $100 \mathrm{~m} / \mathrm{s}$, respectively.

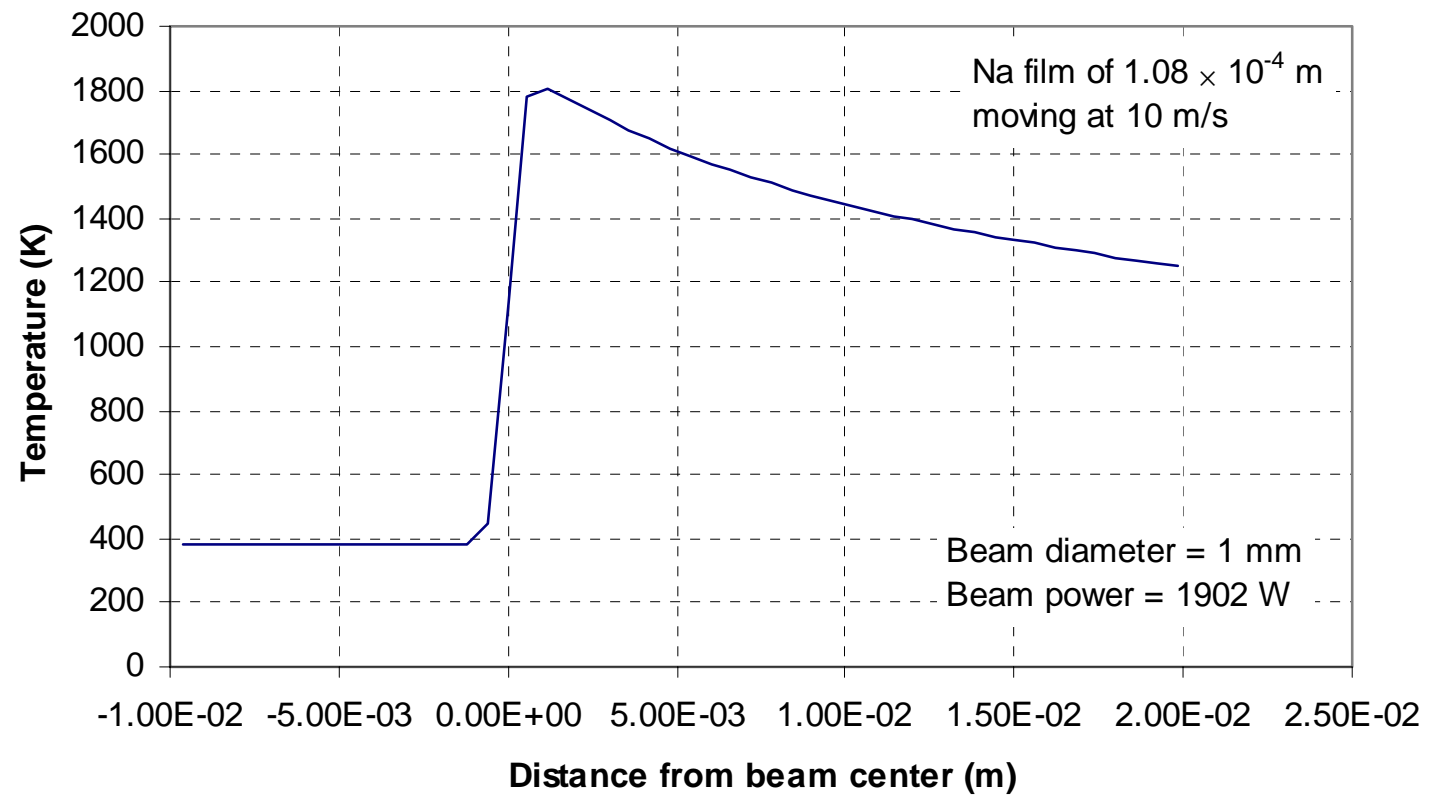

Figure 11. Temperature Distribution at Center (Na at 10 m/s). 


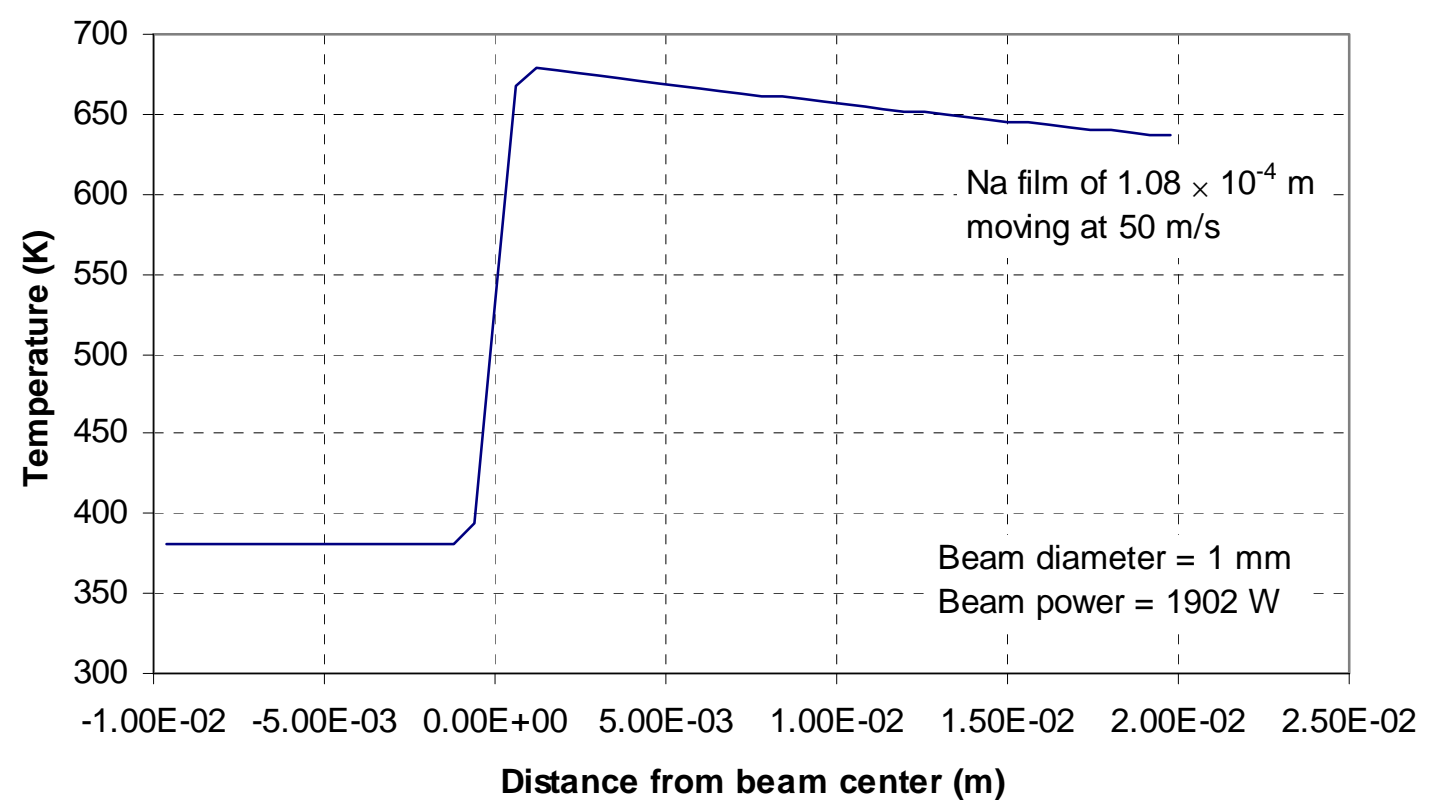

Figure 12. Temperature Distribution at Center (Na at $50 \mathrm{~m} / \mathrm{s}$ ).

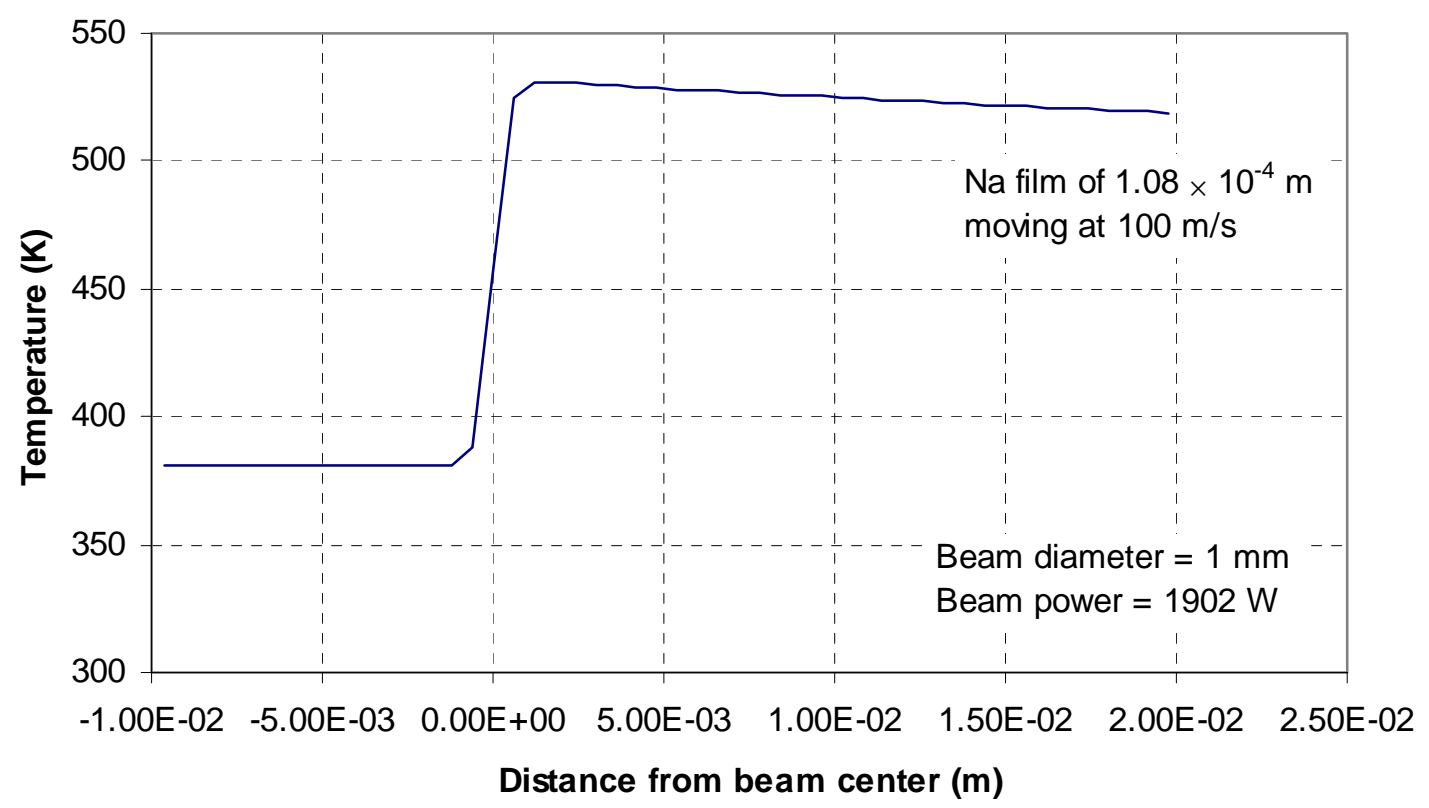

Figure 13. Temperature Distribution at Center (Na at $100 \mathrm{~m} / \mathrm{s}$ ). 
ANL-06/10

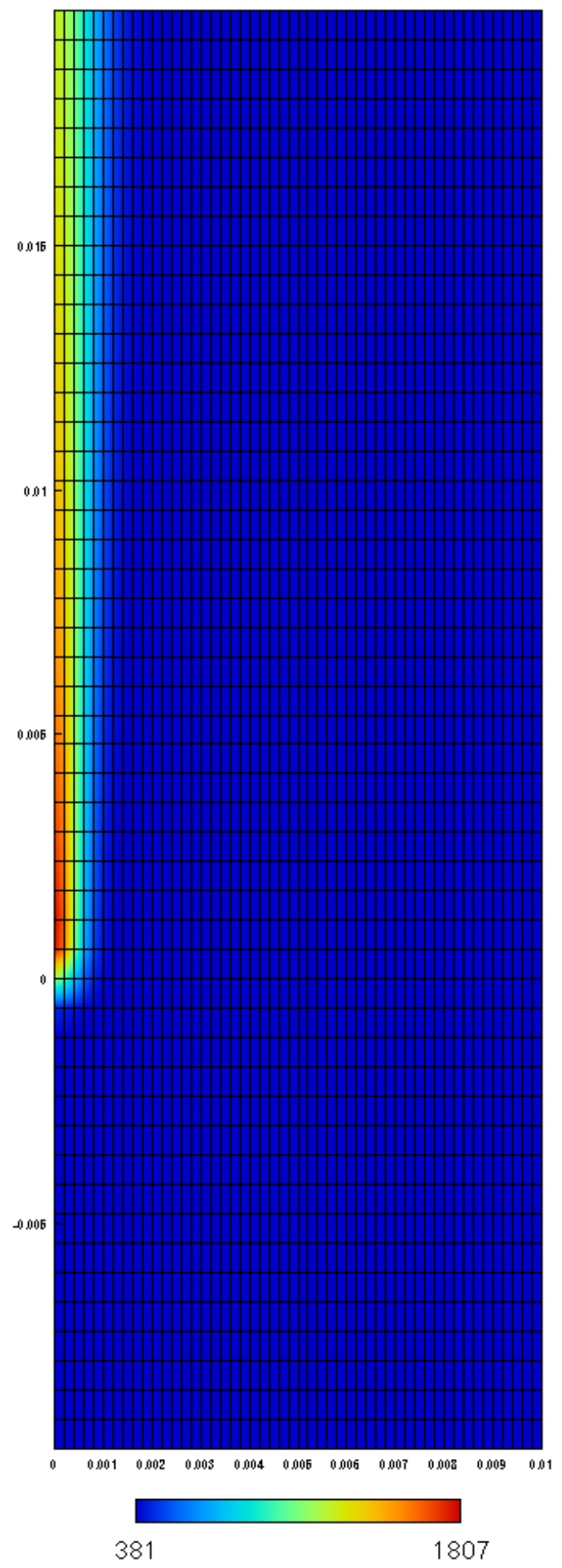

Figure 14. 2D Spatial Temperature Distribution (Na at $10 \mathrm{~m} / \mathrm{s}$ ). 
ANL-06/10

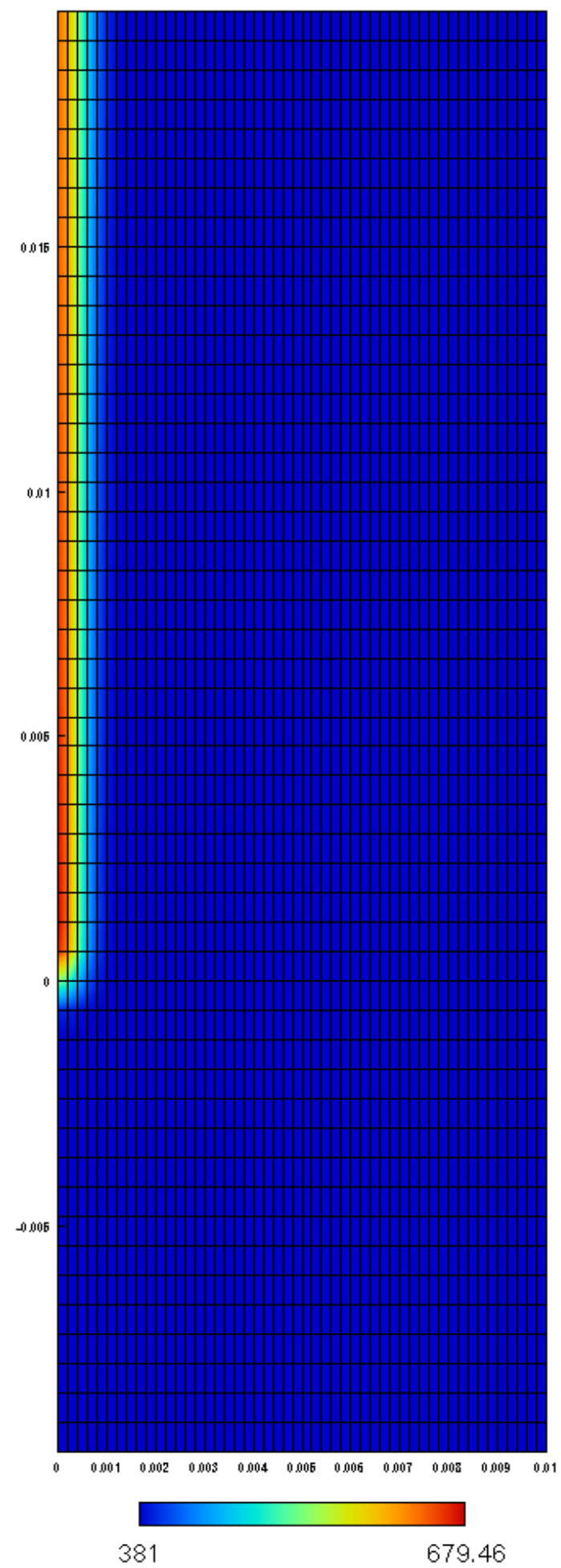

Figure 15. 2D Spatial Temperature Distribution (Na at 50 m/s). 
ANL-06/10

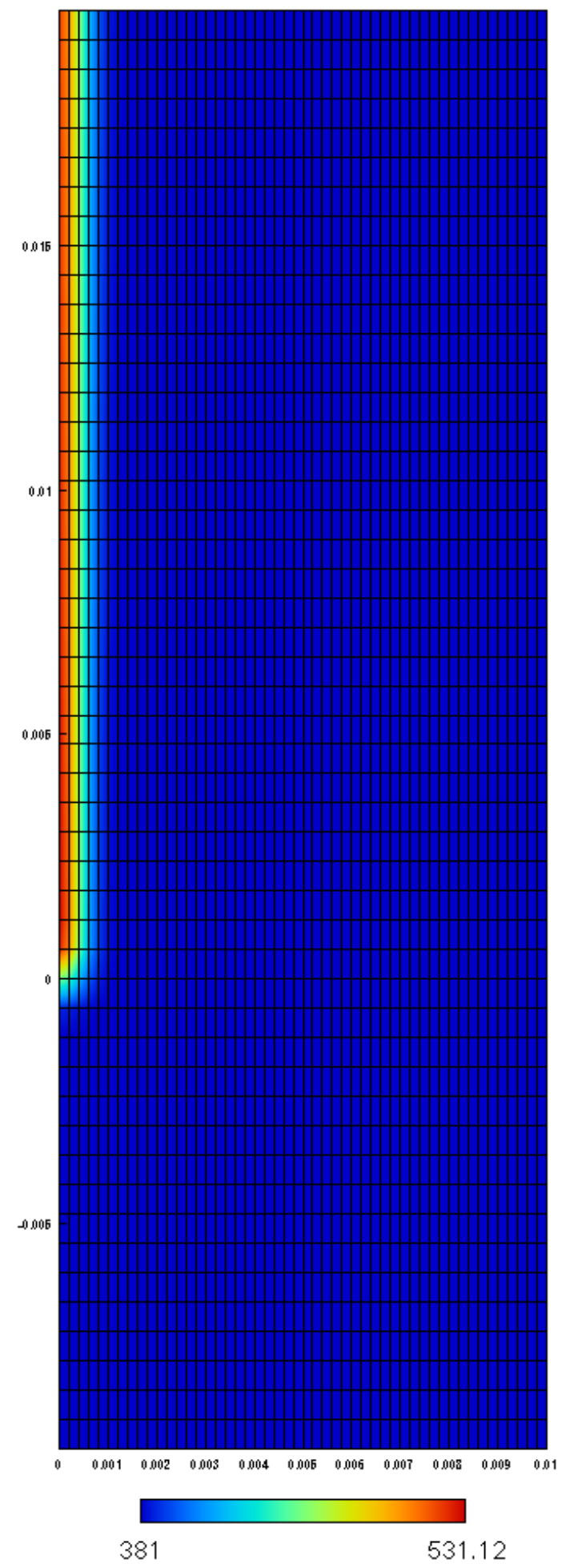

Figure 16. 2D Spatial Temperature Distribution (Na at $100 \mathrm{~m} / \mathrm{s}$ ).

Figures 14-16 indicate that the area where the calculated Na temperature becomes high is relatively narrow. The width of the high temperature area is $\sim \mathrm{x} 1-\mathrm{x} 2$ beam 
diameter. Although liquid stripper concept does not suffer from thermal damaging due to melting, it is prone to release high pressure vapor depending on the vapor pressure of the stripper material. Next figure shows the saturation vapor pressure of Na.

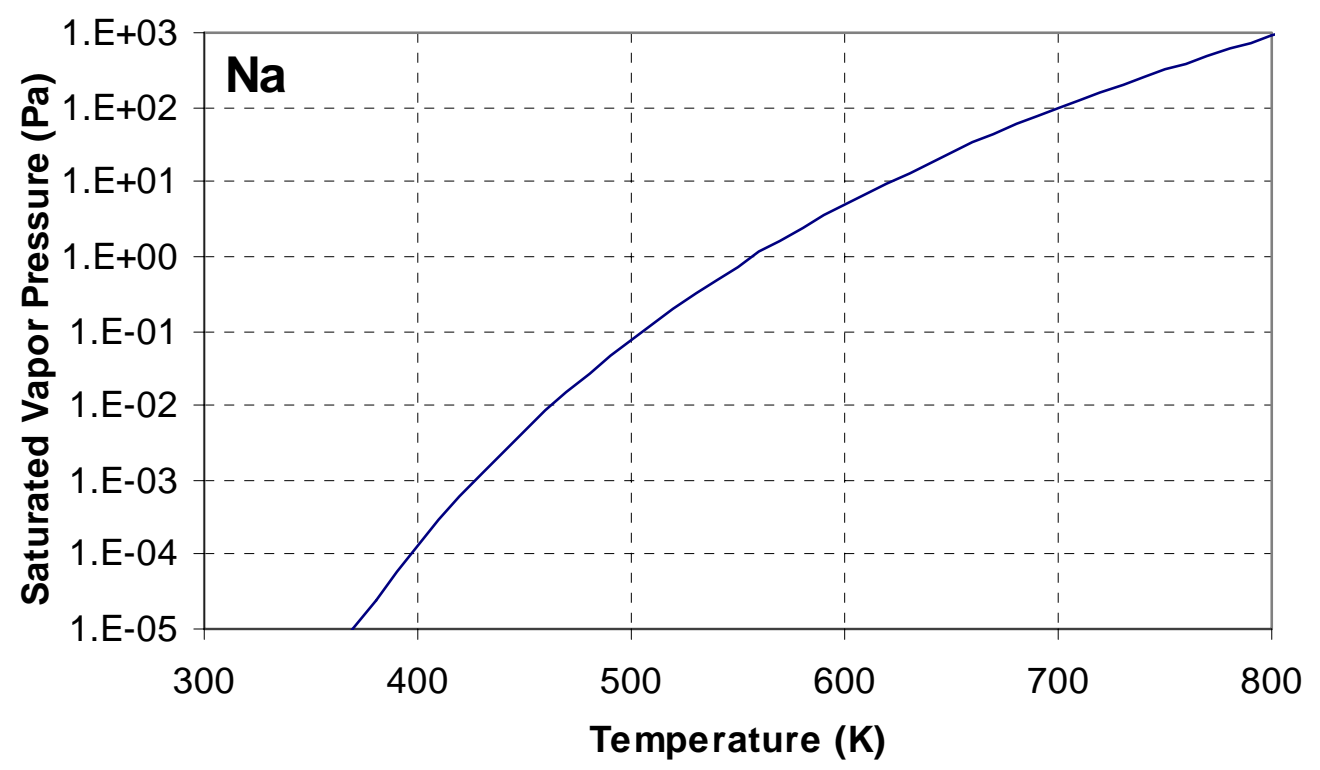

Figure 17. Na saturation vapor pressure as a function of temperature.

This figure shows that the values of the vapor pressure of $\mathrm{Na}$ are $100 \mathrm{~Pa}$ and $\sim 0.5 \mathrm{~Pa}$ at $680 \mathrm{~K}$ and $530 \mathrm{~K}$, respectively. These vapor pressures seem to be too high and may not be acceptable for linac operation.

\section{Titanium and Vanadium}

The initial background temperature for Ti and V was room temperature (298 K). An initial conceptual design for the moving Ti and V stripper was a rotating disk. As the first design, it was assumed that the diameter of the disk was $\sim 0.3 \mathrm{~m}$ and rotation of 3000 rpm from engineering view point. Thickness must have met the nuclear physical requirement ( 15-20 micrometers). The beam spot was located near the edge of the disk. The circumference of the disk was therefore $\sim 1 \mathrm{~m}$ and the beam spot moved at $50 \mathrm{~m} / \mathrm{s}$ on the stripper foil. Figures 18, 19 present the spatial temperature distribution of the disk along the beam line, assuming linear beam spot movement.

Table 2. Properties of Ti and V.

\begin{tabular}{|c|c|c|c|c|c|c|c|c|c|c|c|}
\hline & $Z$ & \begin{tabular}{|l} 
density \\
$\left(\mathrm{kg} / \mathrm{m}^{3}\right)$
\end{tabular} & $\begin{array}{l}\mathrm{k}(\mathrm{W} / \mathrm{m}- \\
\mathrm{K})\end{array}$ & \begin{tabular}{|l}
$\mathrm{Cp}(\mathrm{J} / \mathrm{K}-$ \\
$\mathrm{kg})$
\end{tabular} & $\mathrm{MP}(\mathrm{K})$ & \begin{tabular}{|l|}
$T$ at $1 \mathrm{E}-6$ \\
Torr $(\mathrm{K})$ \\
\end{tabular} & \begin{tabular}{|l|} 
T at $1 \mathrm{E}-5$ \\
Torr $(\mathrm{K})$ \\
\end{tabular} & \begin{tabular}{|l|}
$\mathrm{T}$ at $1 \mathrm{E}-4$ \\
Torr $(\mathrm{K})$ \\
\end{tabular} & \begin{tabular}{|l|}
$T$ at $1 \mathrm{E}-3$ \\
Torr $(\mathrm{K})$ \\
\end{tabular} & $\begin{array}{l}\text { T at } 1 \\
\text { Torr }(\mathrm{K}) \\
\end{array}$ & $\mathrm{BP}(\mathrm{K})$ \\
\hline $\mathrm{Ti}$ & 22 & 4507 & 21.9 & 520 & 1941 & 1500 & 1600 & 1715 & 1850 & 2450 & 3560 \\
\hline V & 23 & 6110 & 31 & 489 & 2183 & & & & 1950 & 2550 & 3680 \\
\hline
\end{tabular}




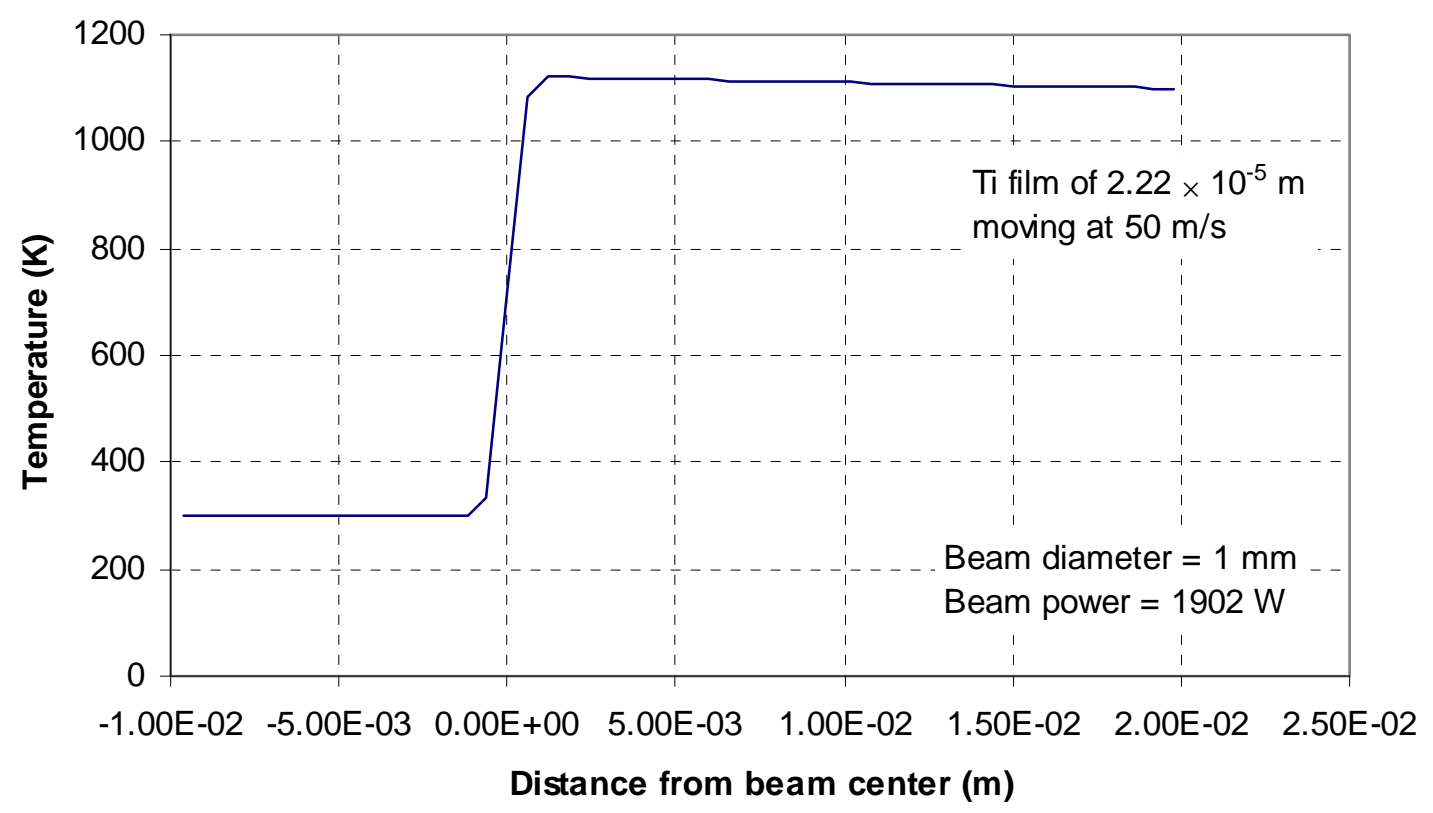

Figure 18. Temperature Distribution at Center ( $\mathrm{Ti}$ at $50 \mathrm{~m} / \mathrm{s})$.

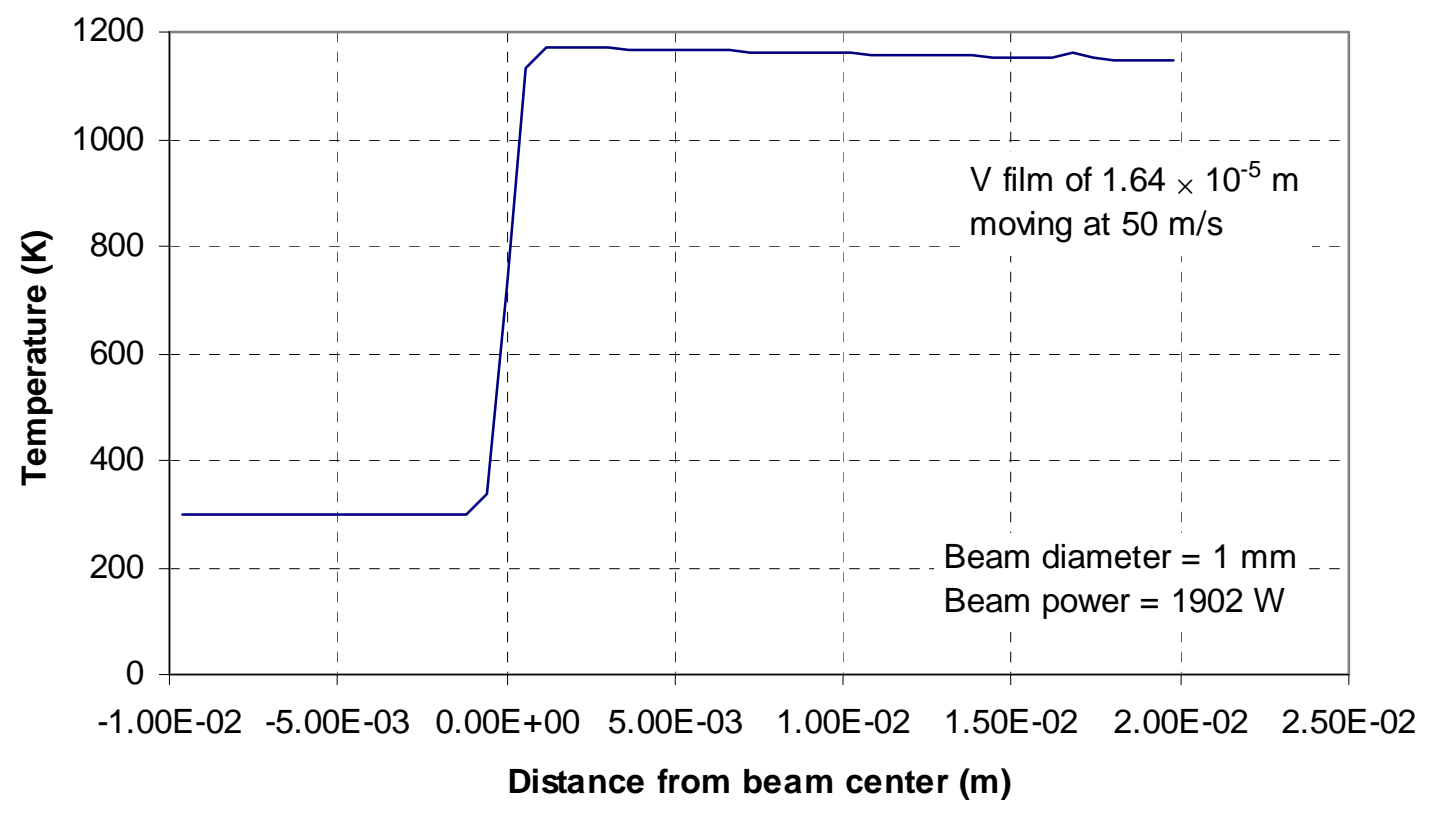

Figure 19. Temperature Distribution at Center (V at $50 \mathrm{~m} / \mathrm{s})$.

These figures show that the calculated maximum temperatures of the stripper disk after the first beam shot are $\sim 1120 \mathrm{~K}$ and $\sim 1170 \mathrm{~K}$ for Ti and V at $50 \mathrm{~m} / \mathrm{s}$, respectively. Instantaneous temperature jumps after first beam shot are $\sim 820 \mathrm{~K}$ and $\sim 870 \mathrm{~K}$ for Ti and 
$\mathrm{V}$, respectively. Next figures show 2D temperature distribution of the stripper moving at $50 \mathrm{~m} / \mathrm{s}$ near the beam spot after the first beam shot.

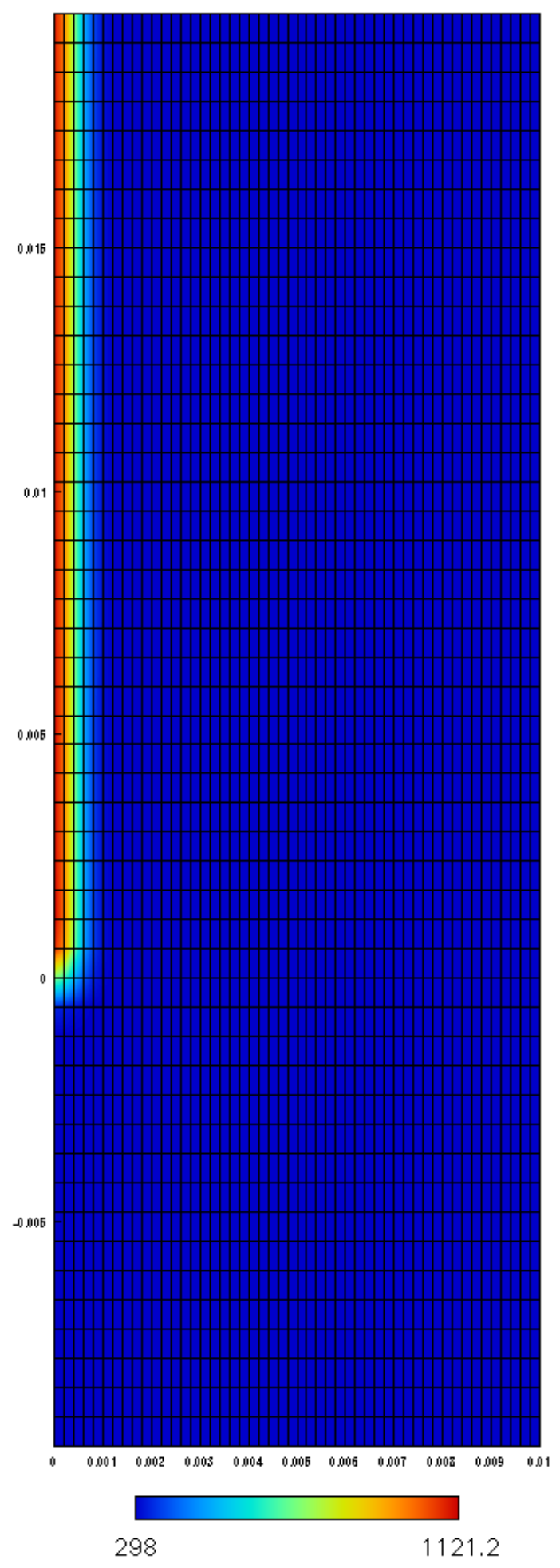

Figure 20. 2D Spatial Temperature Distribution (Ti at $50 \mathrm{~m} / \mathrm{s}$ ). 
ANL-06/10

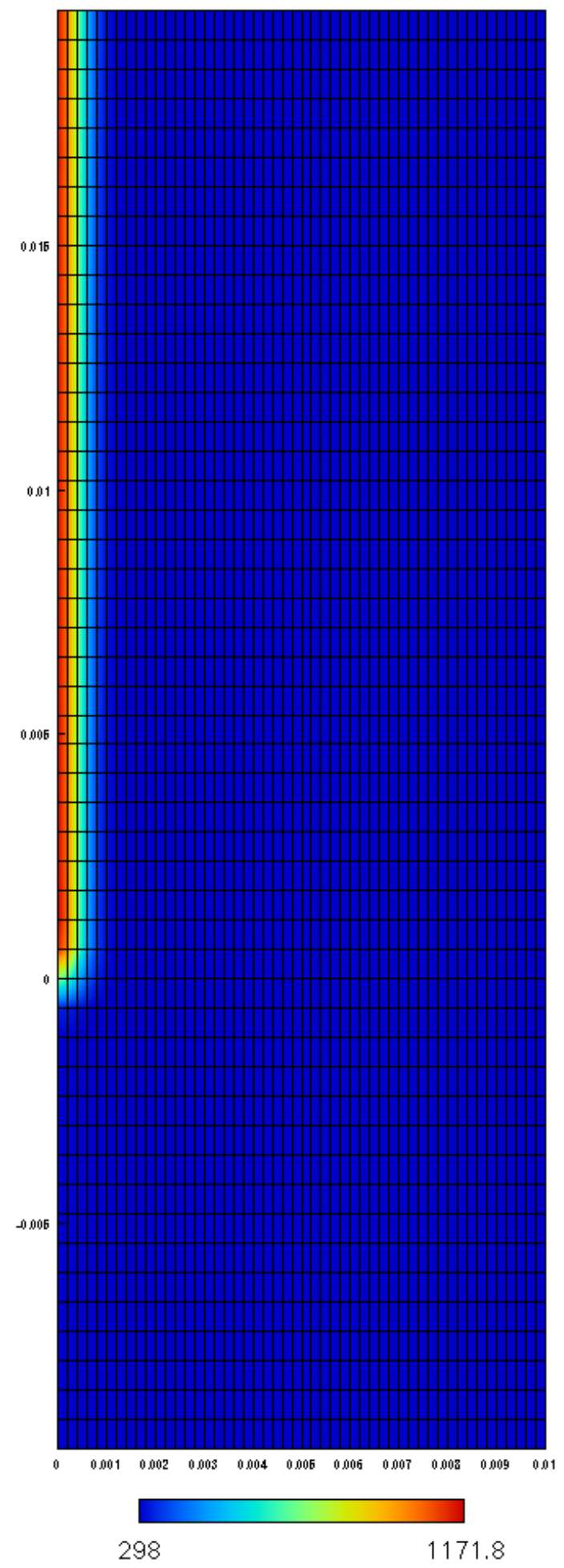

Figure 21. 2D Spatial Temperature Distribution ( $\mathrm{V}$ at $50 \mathrm{~m} / \mathrm{s}$ ).

Again, these figures indicate that the area where temperature becomes high is relatively narrow. The width of the high temperature area in the proximity of the beam 
spot is limited within $\sim \mathrm{x} 1-\mathrm{x} 2$ beam diameter. For the rotating disk stripper, the same location will eventually be irradiated by the beam again. For example, if the disk is not wobbled in radial direction, the same spot on the disk will be beamed again after one rotation. The next figures show how thermal energy spreads in the disk by conduction when no radiation heat loss to the outside was assumed. It must be noted that if no wobbling was assumed, the second initial temperature for the beam spot would be $\sim 700$ $\mathrm{K}$, which is $\sim 400 \mathrm{~K}$ higher than the first initial temperature. The width of the heated area became $\sim 4-5 \mathrm{~mm}$ after one rotation due to spreading of thermal energy by conduction through the disk. This means that if the disk is shifted in radial direction by more than 2-3 mm after one rotation, the beam will hit the place that has not been thermally affected by the beam. Similar results and observations were also obtained for the $\mathrm{V}$ disk case.

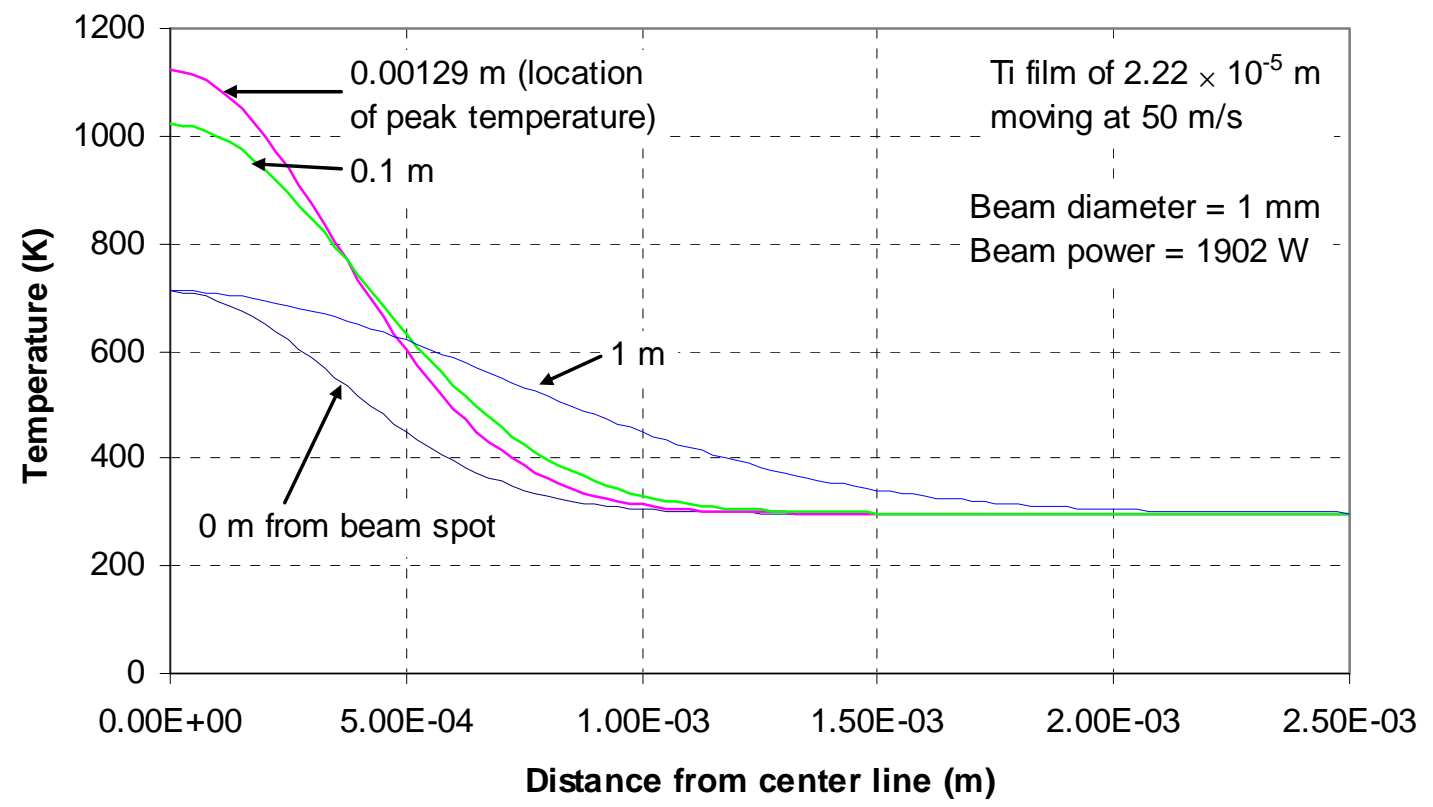

Figure 22. Temperature distribution across the stripper perpendicular to the direction of motion for Ti at $50 \mathrm{~m} / \mathrm{s}$. 


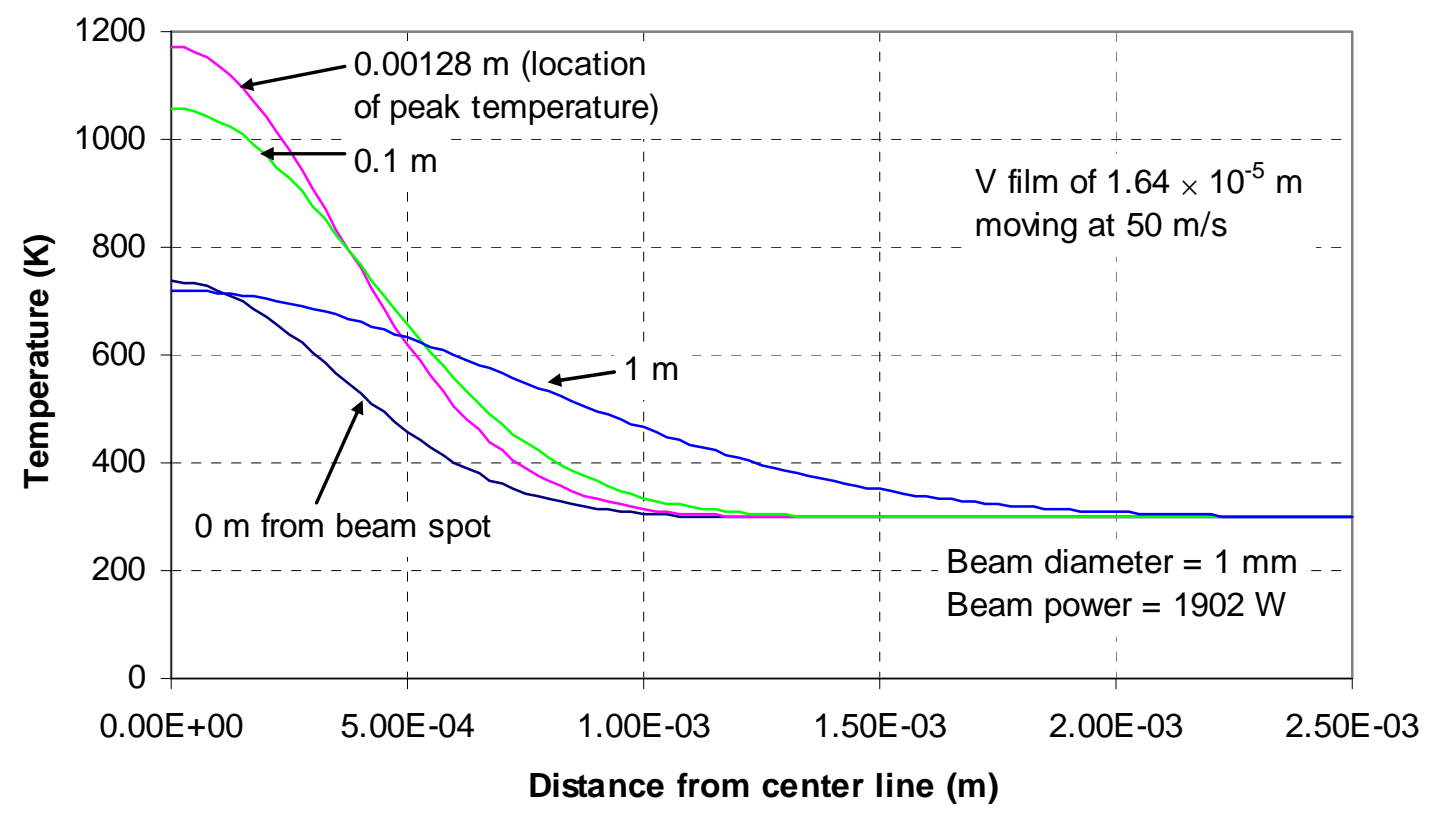

Figure 23. Temperature distribution across the stripper perpendicular to the direction of motion for $\mathrm{V}$ at $50 \mathrm{~m} / \mathrm{s}$.

Eventually, the radiation heat loss from the surface of the disk must balance the thermal energy deposition from the beam that is $\sim 2000 \mathrm{~W}$. For a simple estimation, the stripper disk was assumed to be a disk whose circumference with a certain width was held at a constant, uniform temperature held in vacuum whose surrounding temperature was the room temperature. The disk may be blackened to increase the emissivity to enhance radiative heat transfer. The enhanced emissivity of 0.8 was used in the following calculations. Both sides of the disk were assumed to contribute radiation.

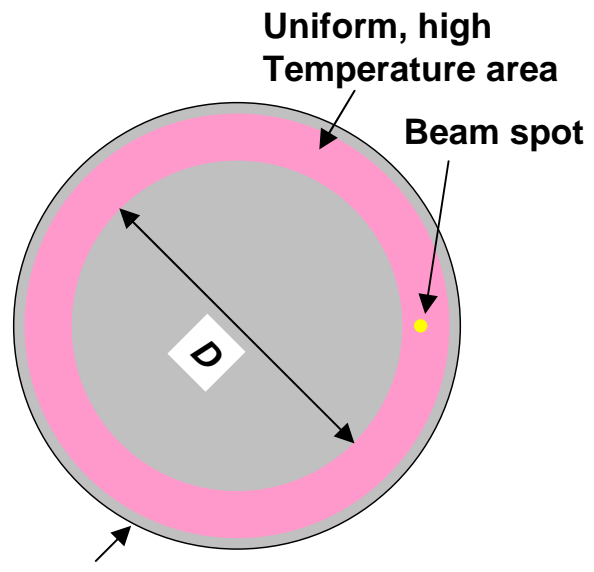

Blackened disk

Figure 24. Modeled rotating disk stripper for radiation analysis. 
The amount of heat removed by radiation was calculated as,

$$
Q_{r a d}(T)=A \sigma \varepsilon F\left(T^{4}-T_{B G}{ }^{4}\right),
$$

where $A$ is the surface area, $\sigma$ is Stephan-Boltzmann constant $\left(=5.67 \times 10^{-8} \mathrm{~W} / \mathrm{m}^{2}-\mathrm{K}^{4}\right)$, $\varepsilon$ is an emissivity of the wall ( 0.8 for all cases), $F$ is a view factor (taken to be 1 for all cases), and $T_{B G}$ is the background temperature (taken to be $300 \mathrm{~K}$ for all cases).

Table 3. Required surface temperature to radiatively remove $2000 \mathrm{~W}$.

\begin{tabular}{|l|r|r|r|r|r|r|r|}
\hline inner radius $(\mathrm{m})$ & 0.15 & 0.15 & 0.15 & 0.15 & 0.3 & 0.3 & 0.3 \\
\hline width of hot area $(\mathrm{m})$ & 0.01 & 0.025 & 0.05 & 0.075 & 0.01 & 0.025 & 0.05 \\
\hline emissivity & 0.8 & 0.8 & 0.8 & 0.8 & 0.8 & 0.8 & 0.8 \\
\hline Background $(\mathrm{K})$ & 300 & 300 & 300 & 300 & 300 & 300 & 300 \\
\hline radiation $(\mathrm{W})$ & 2000 & 2000 & 2000 & 2000 & 2000 & 2000 & 2000 \\
\hline & & & & & & & \\
\hline temperature required $(\mathrm{K})$ & $\mathbf{1 2 2 7 . 7}$ & $\mathbf{9 6 6 . 3}$ & $\mathbf{7 9 9 . 8}$ & $\mathbf{7 1 2 . 4}$ & $\mathbf{1 0 3 7 . 5}$ & $\mathbf{8 2 2 . 3}$ & $\mathbf{6 8 8 . 0}$ \\
\hline
\end{tabular}

For linac operation, low vapor pressure in the cavity is desirable $\left(\sim 10^{-4} \mathrm{~Pa}\right)$. For $\mathrm{Ti}$, upper limit temperature was set at $1500 \mathrm{~K}$ and $1600 \mathrm{~K}$ for V. Since instantaneous temperature increases are $\sim 820 \mathrm{~K}$ and $\sim 870 \mathrm{~K}$ for $\mathrm{Ti}$ and $\mathrm{V}$, respectively, the highest background temperature for both cases needs to be $<\sim 700 \mathrm{~K}$. One more important point is that the beam line must cross after one rotation when the direction of shifting changes at the edges of the hot area (see Figure 25). This means that the point at which the beam line crosses experiences beam shot twice after only one rotation ( $\sim 1 \mathrm{~m}$ after first beam shot for a disk with $\sim 0.3 \mathrm{~m}$ diameter). Therefore, an additional $\sim 700 \mathrm{~K}$ temperature increase has to be added. As a result, it is not possible to maintain the temperature at the beam cross point below $1500 \mathrm{~K}$ for Ti or $1600 \mathrm{~K}$ for $\mathrm{V}$, unless disk size and disk rotation velocity are appropriately adjusted, which may create engineering issues.

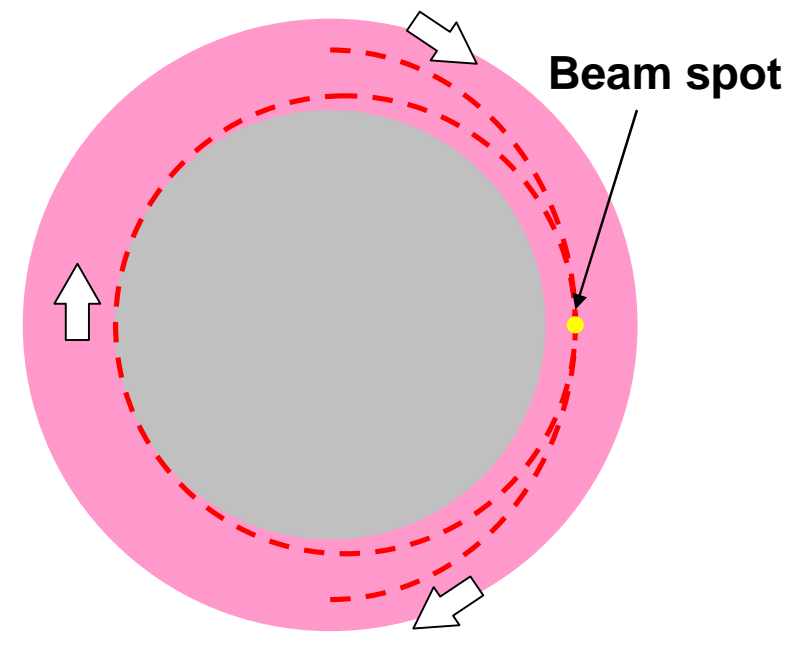

Figure 25. Beam path when direction of shifting changes.

It must be noted that since the average temperature of the hot area will be higher than the uniform background temperature calculated in the above table due to heating 
from beam irradiation, this estimation is expected to be somewhat conservative. It is apparent that the width of the hot area needs to be $>\sim 0.05 \mathrm{~m}$, unless the disk size is much larger. Since it is desirable to shift the beam line by $\sim 2-3 \mathrm{~mm}$ after each rotation to avoid producing hot spots, 10-20 beam lines can fit within the width of the hot area.

\section{References}

http://dnr080.jinr.ru/lise/lise.html (LISE++).

Pittaway, L. G., (1964) "The temperature distributions in thin foil and semi-infinite targets bombarded by an electron beam,” Brit. J. Appl. Phys., v 15, pp967-982.

Press, W. H., Teukolsky, S. A., Vetterling, W. T., and Flannery, B. P., (1992) Numerical Recipes in FORTRAN: The Art of Scientific Computing, Second Edition, Cambridge University Press.

http://heliumclub.usc.edu/Refs/Vapor.htm (vapor pressure data for Ti).

http://www.puretechinc.com/data_sheets/vanadium.htm (vapor pressure data for V). 


\section{Appendix}

\section{Fortran program XTFXR}

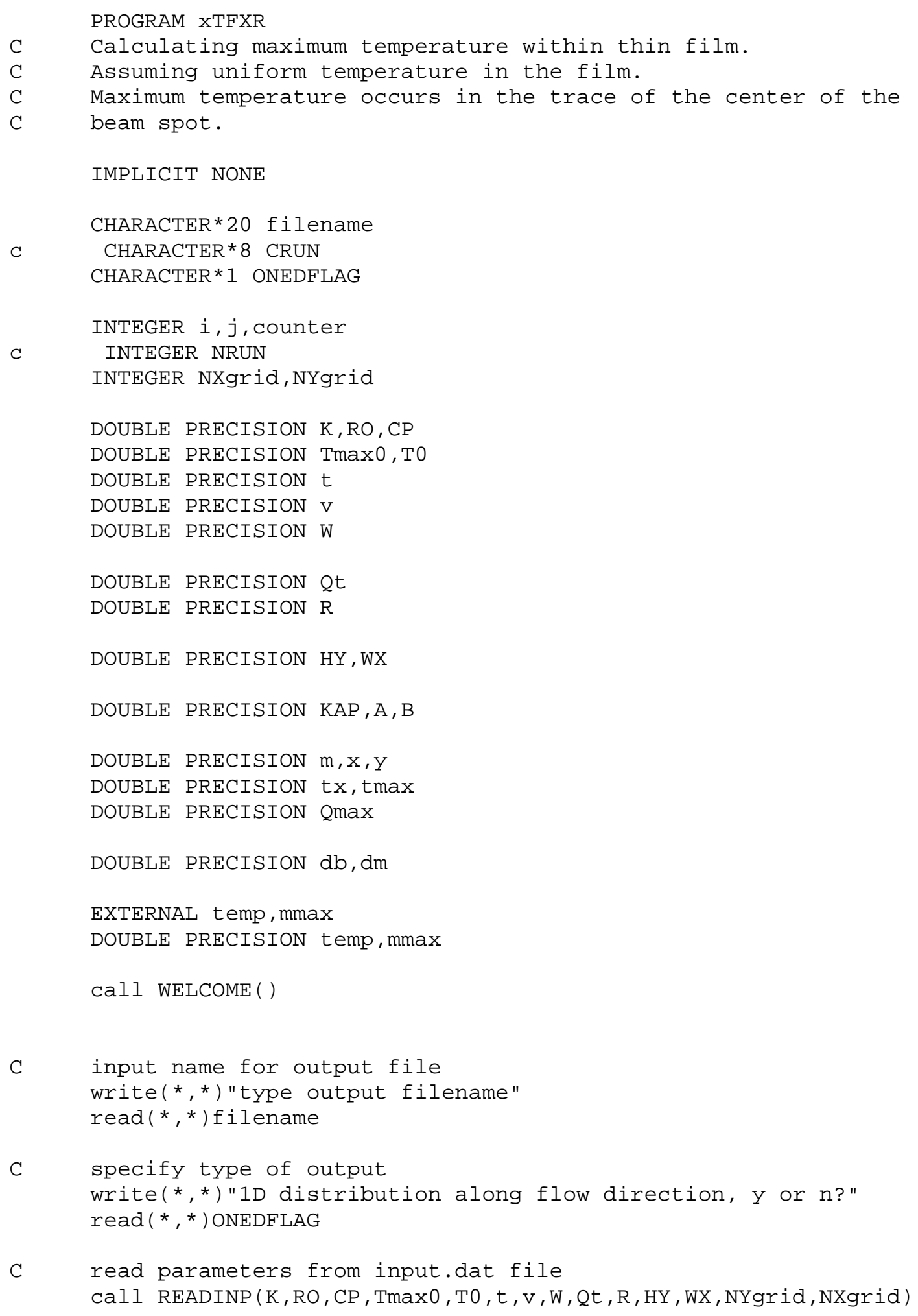




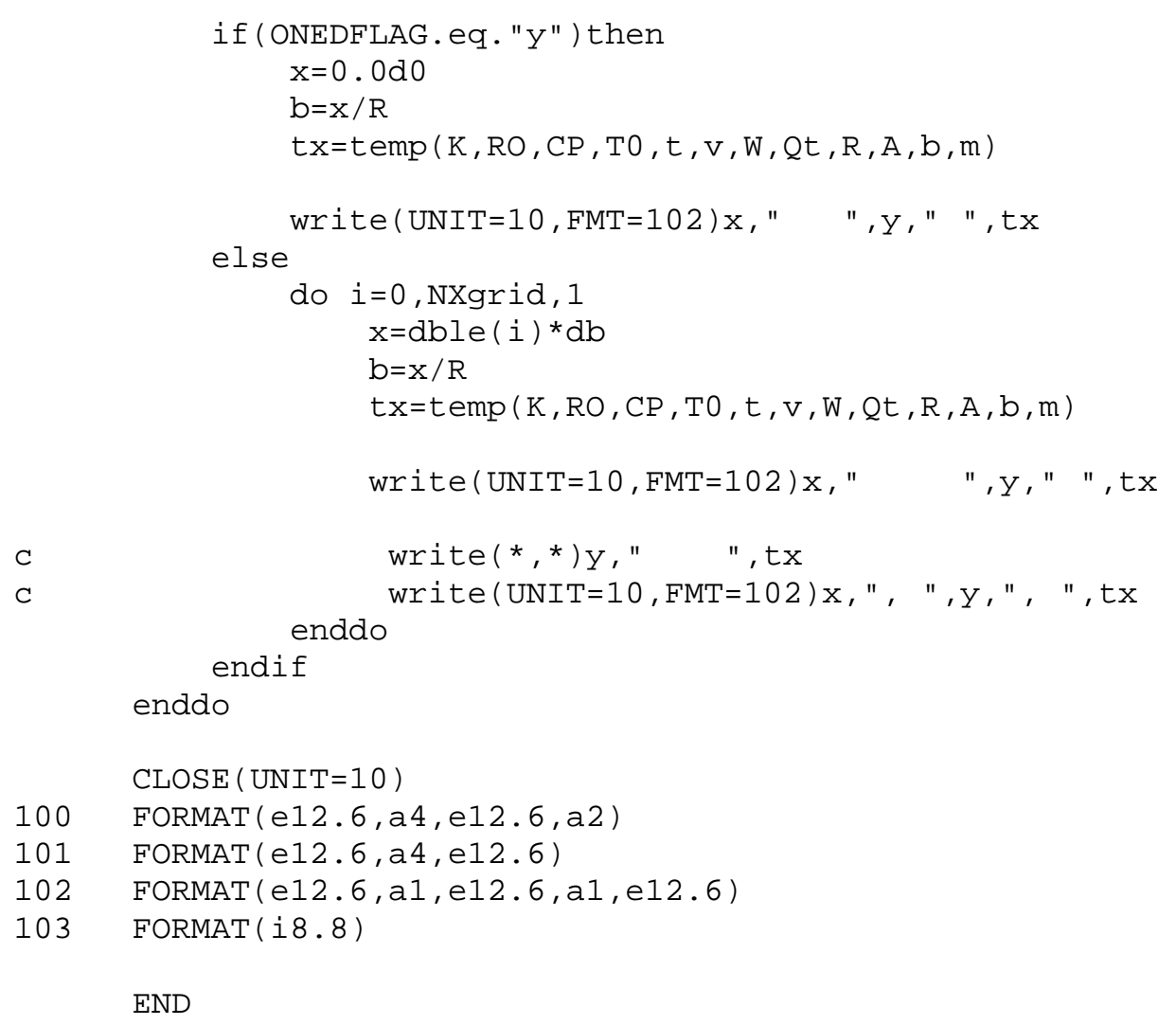

\section{Fortran subroutine WELCOME}

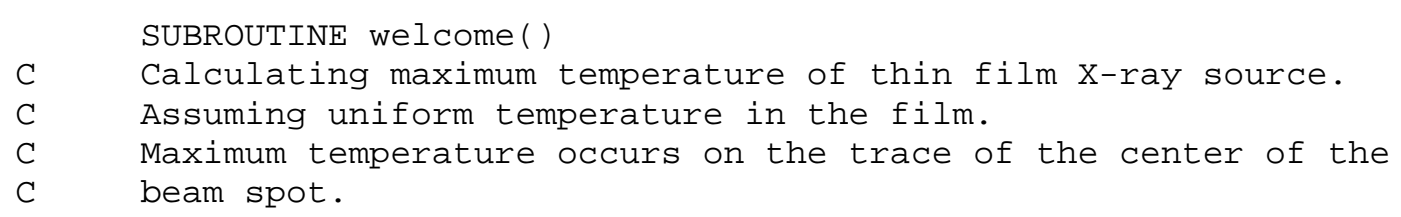

IMPLICIT NONE

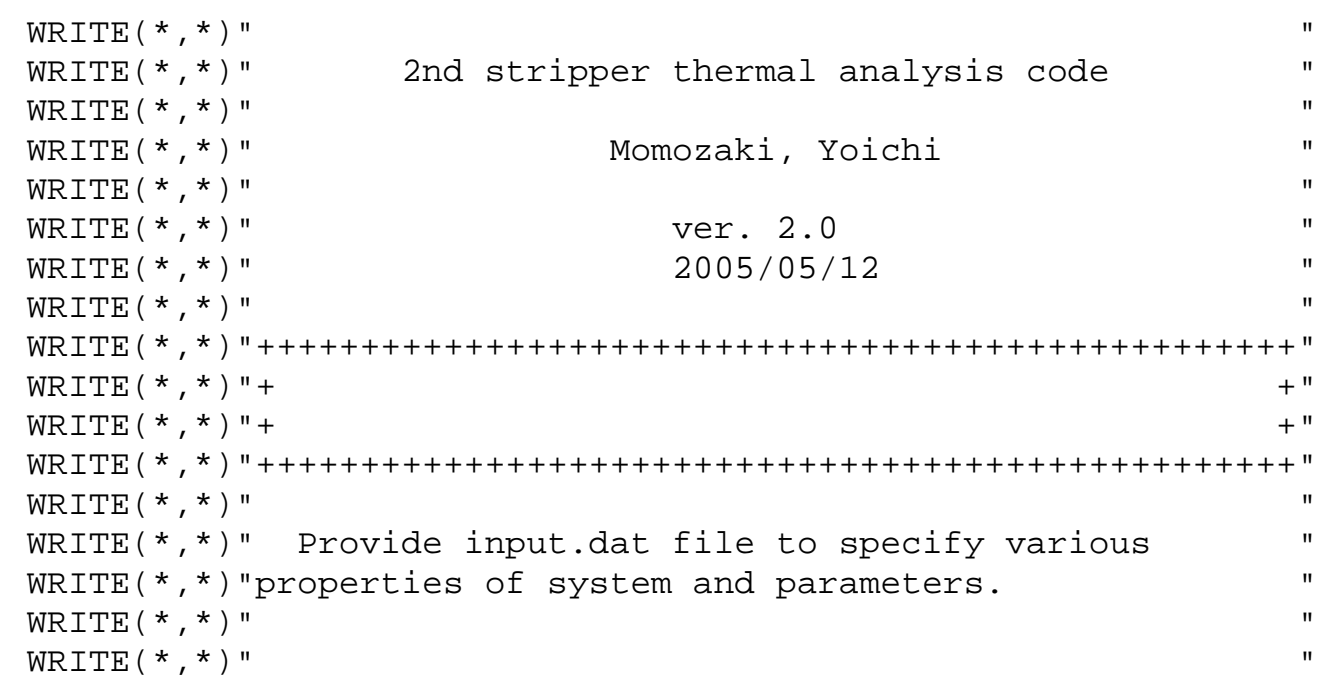




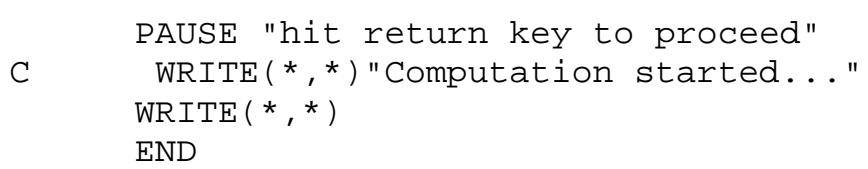

\section{Fortran subroutine READINP}

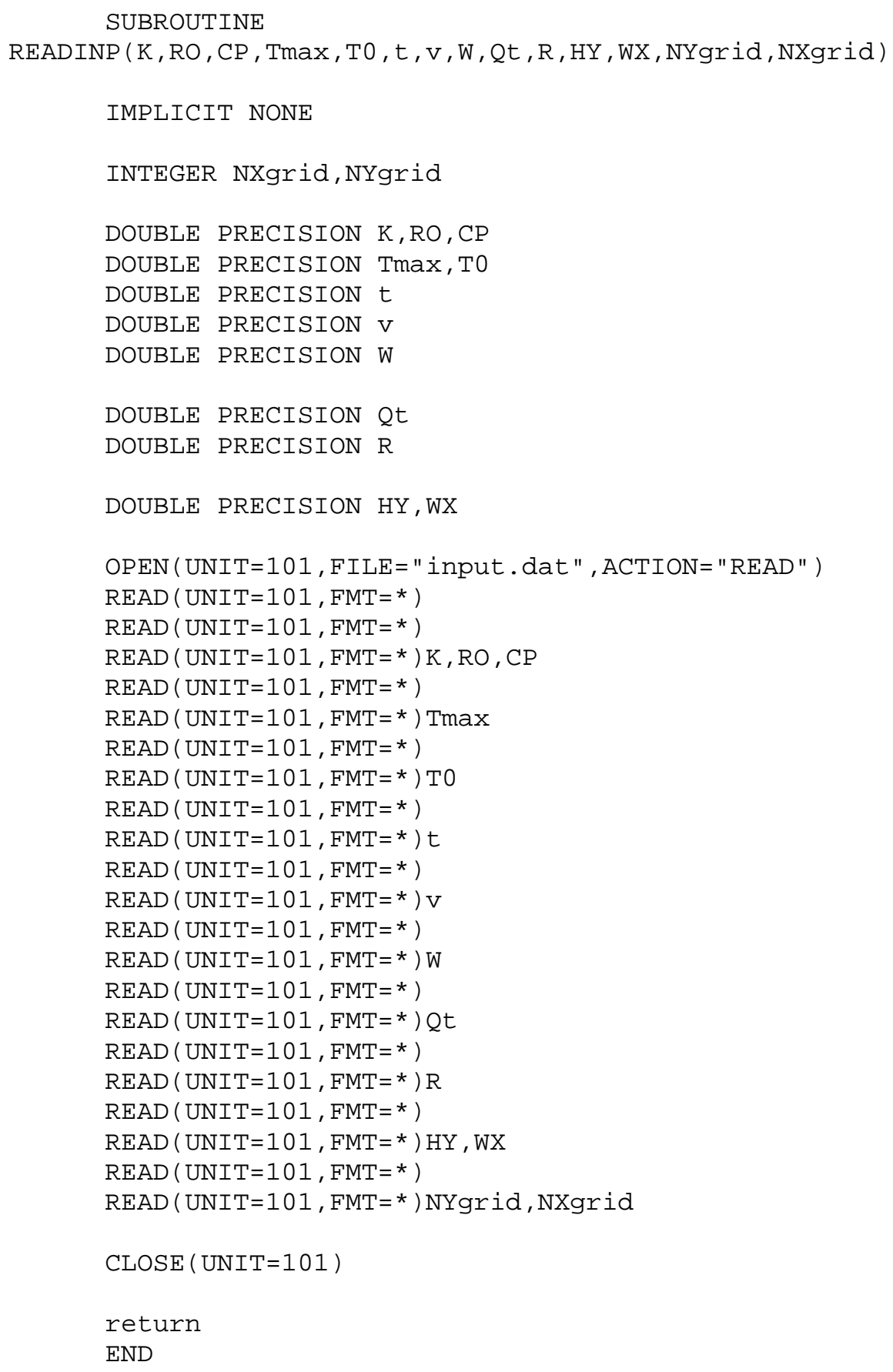




\section{Fortran functions MMAX, INTEG2, FUNCT2, DZRIDDR2}

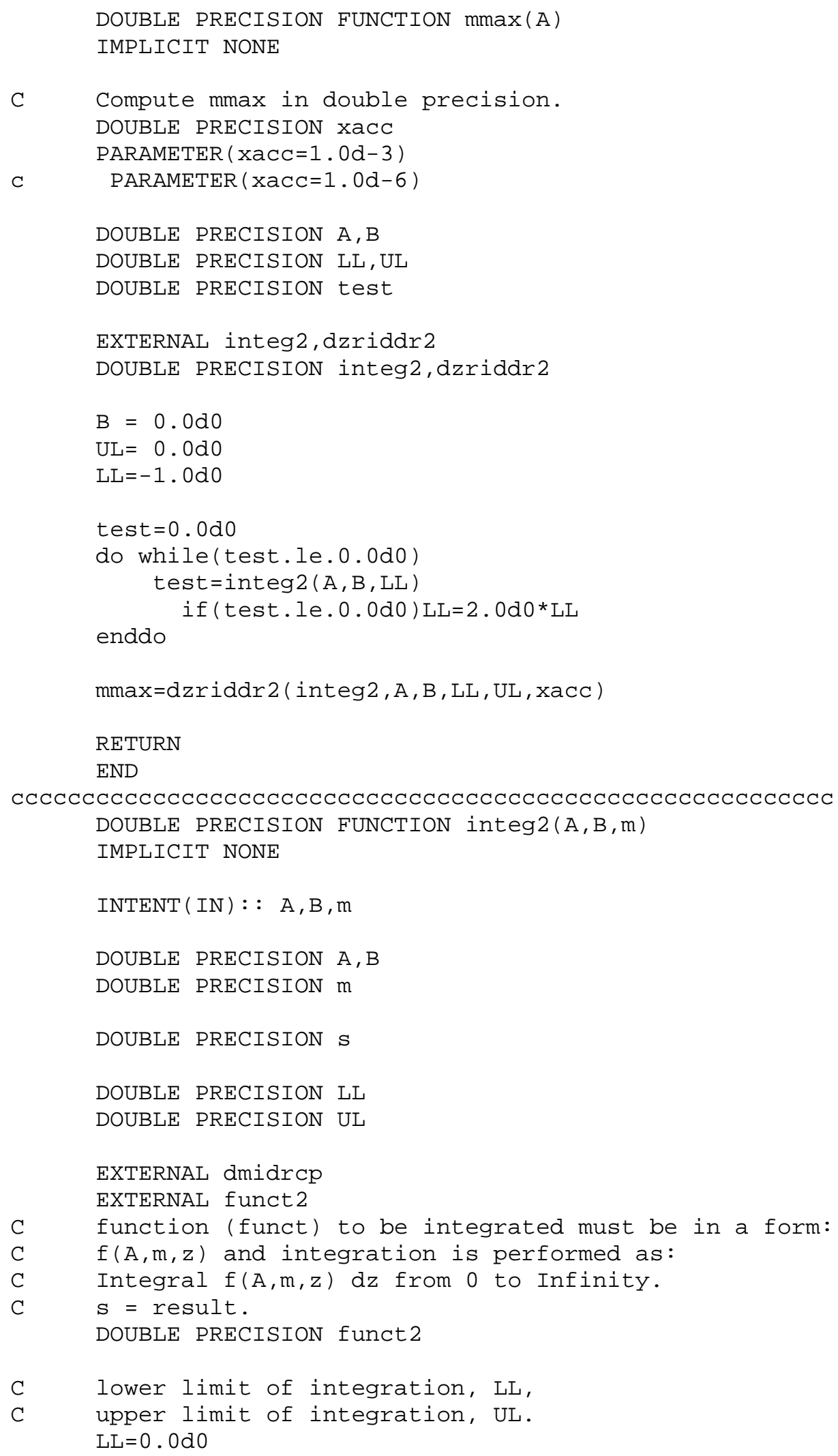




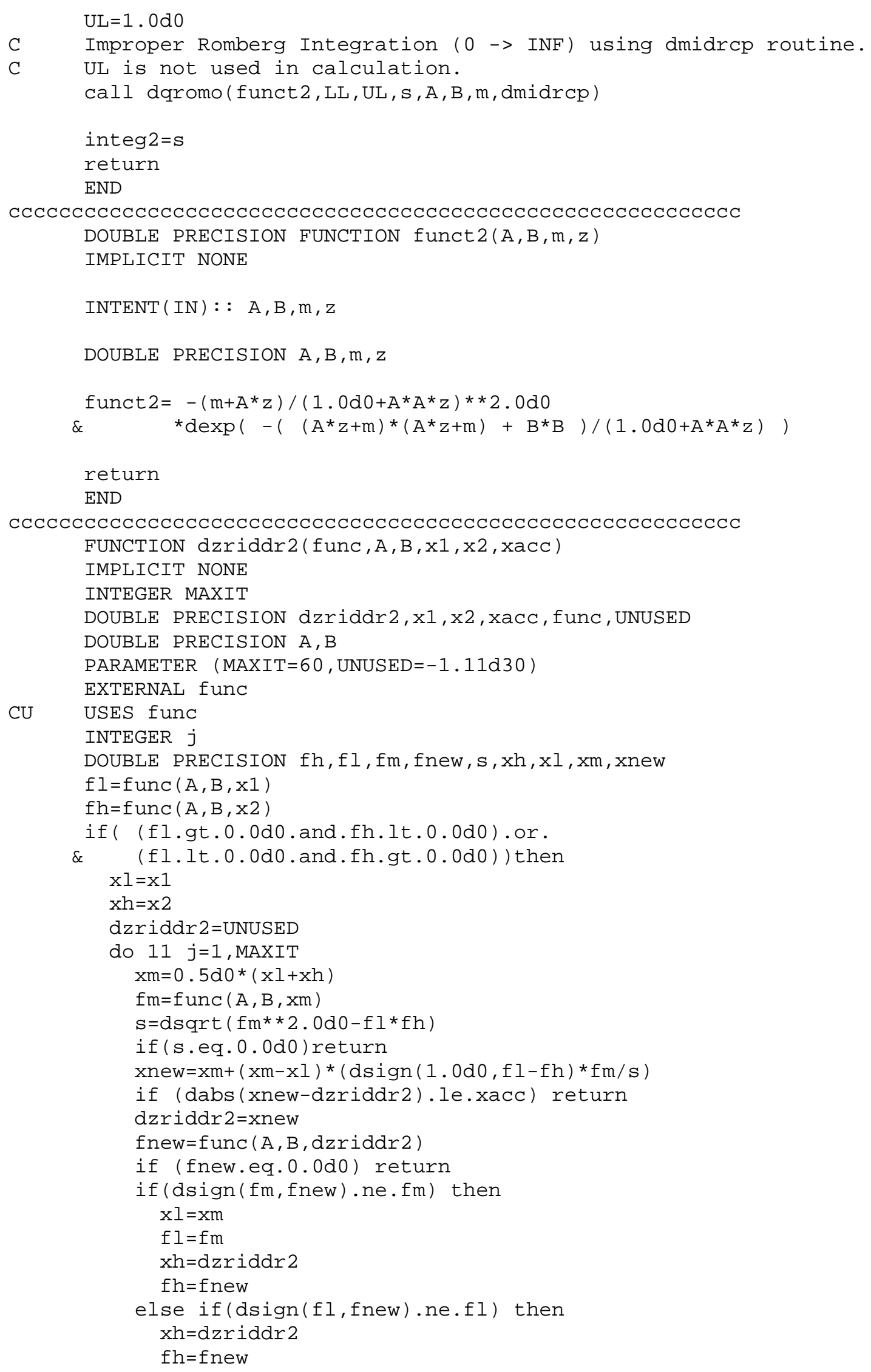


11

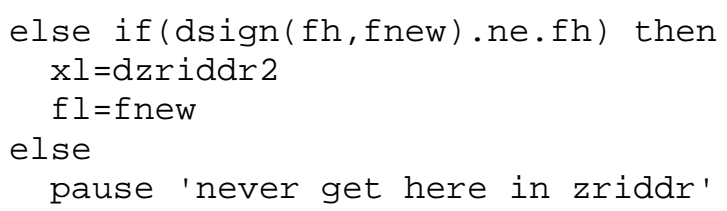

$$
\text { endif }
$$

$$
\begin{aligned}
& \text { if }(\text { dabs }(x h-x l) \cdot l e \cdot x a c c) \text { return } \\
& \text { continue }
\end{aligned}
$$

pause 'dzriddr2 exceed maximum iterations'

else if (fl.eq.0.0dO) then

dzriddr $2=x 1$

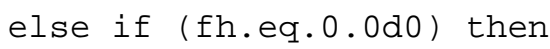

dzriddr $2=x 2$

else

pause 'root must be bracketed in dzriddr2'

endif

return

END

\section{Fortran function TEMP}

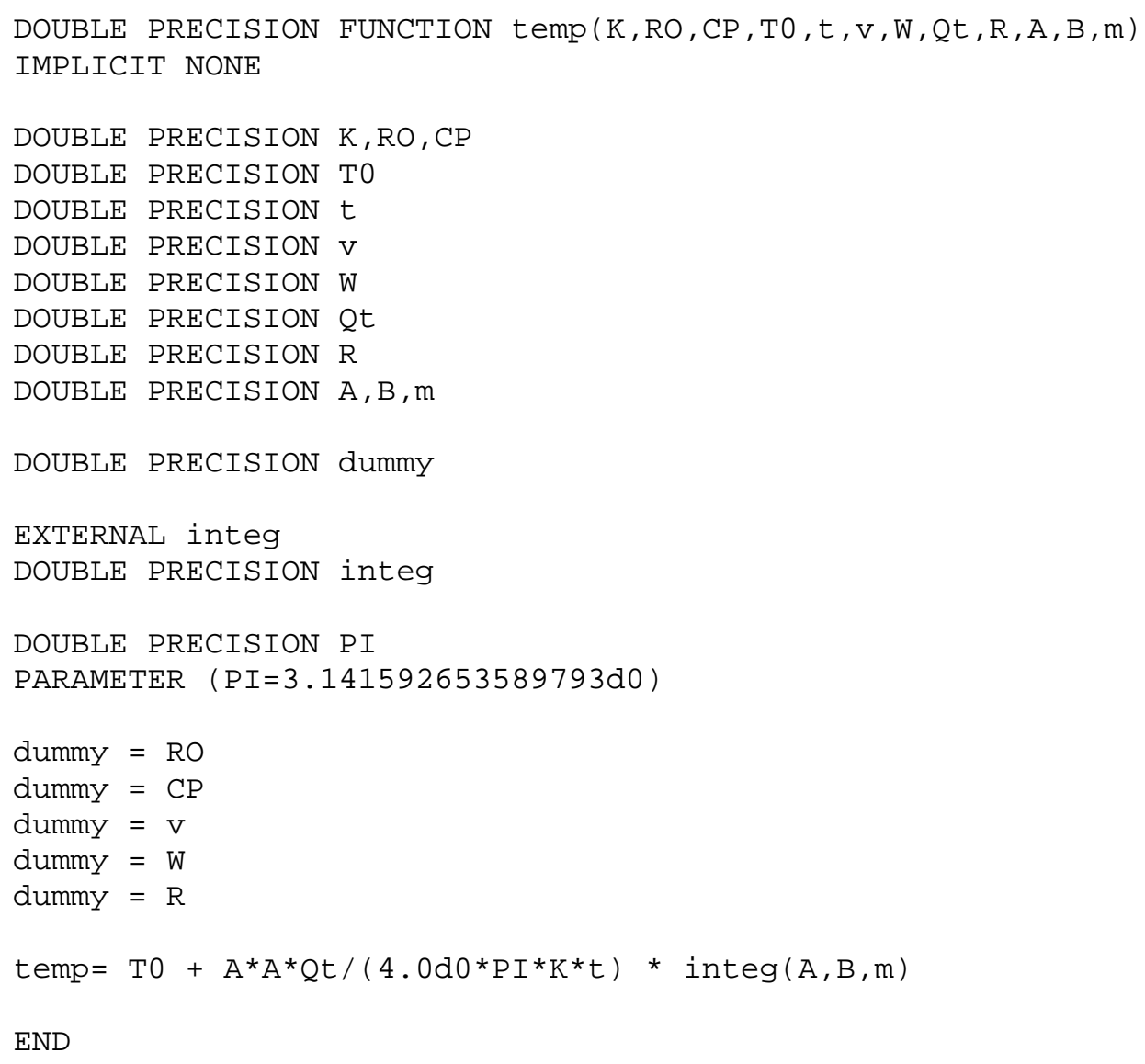

Fortran function INTEG, subroutines DQROMO, POLINT, DMIDRCP, DMIDEXP DOUBLE PRECISION FUNCTION integ $(A, B, m)$ 


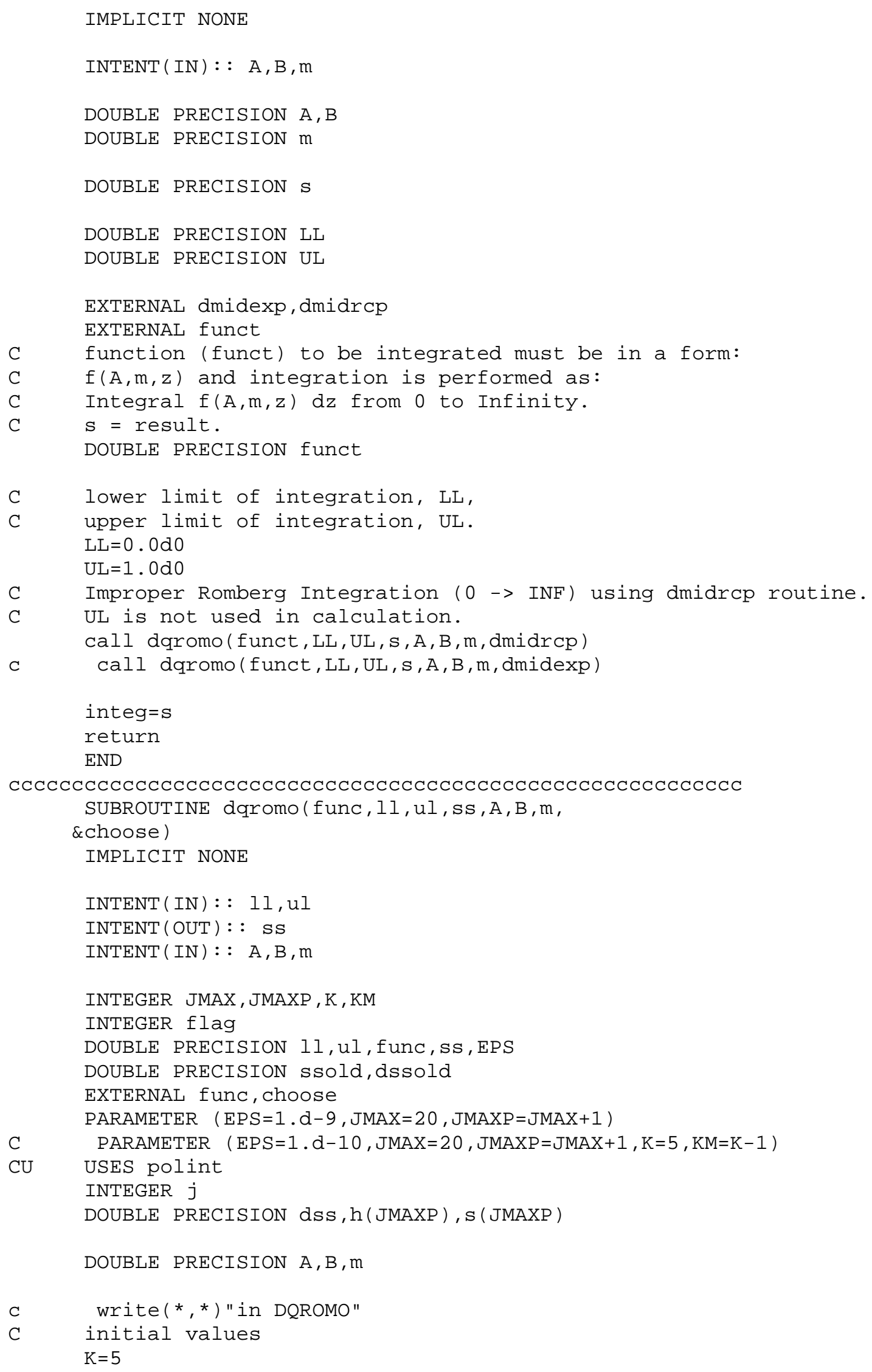




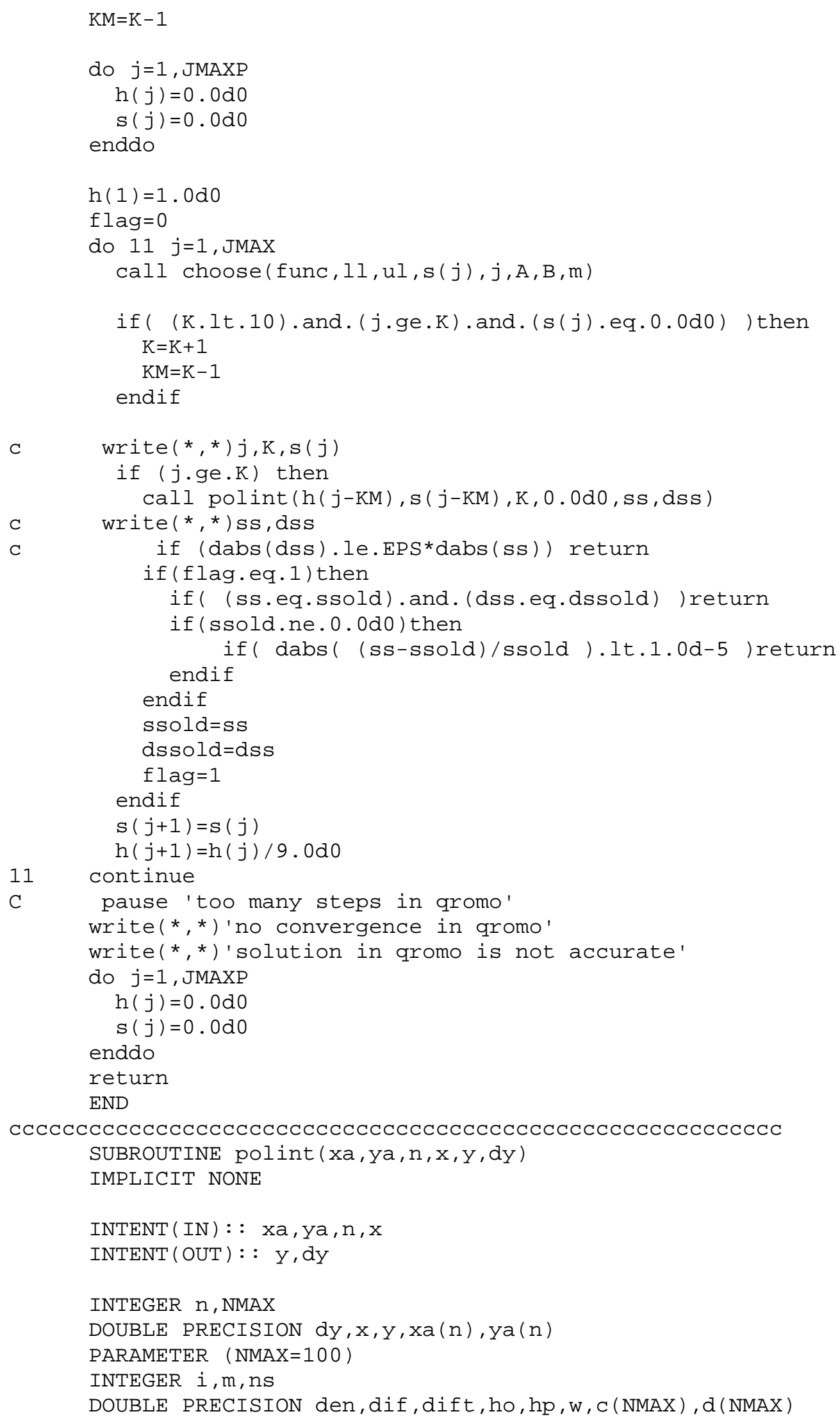




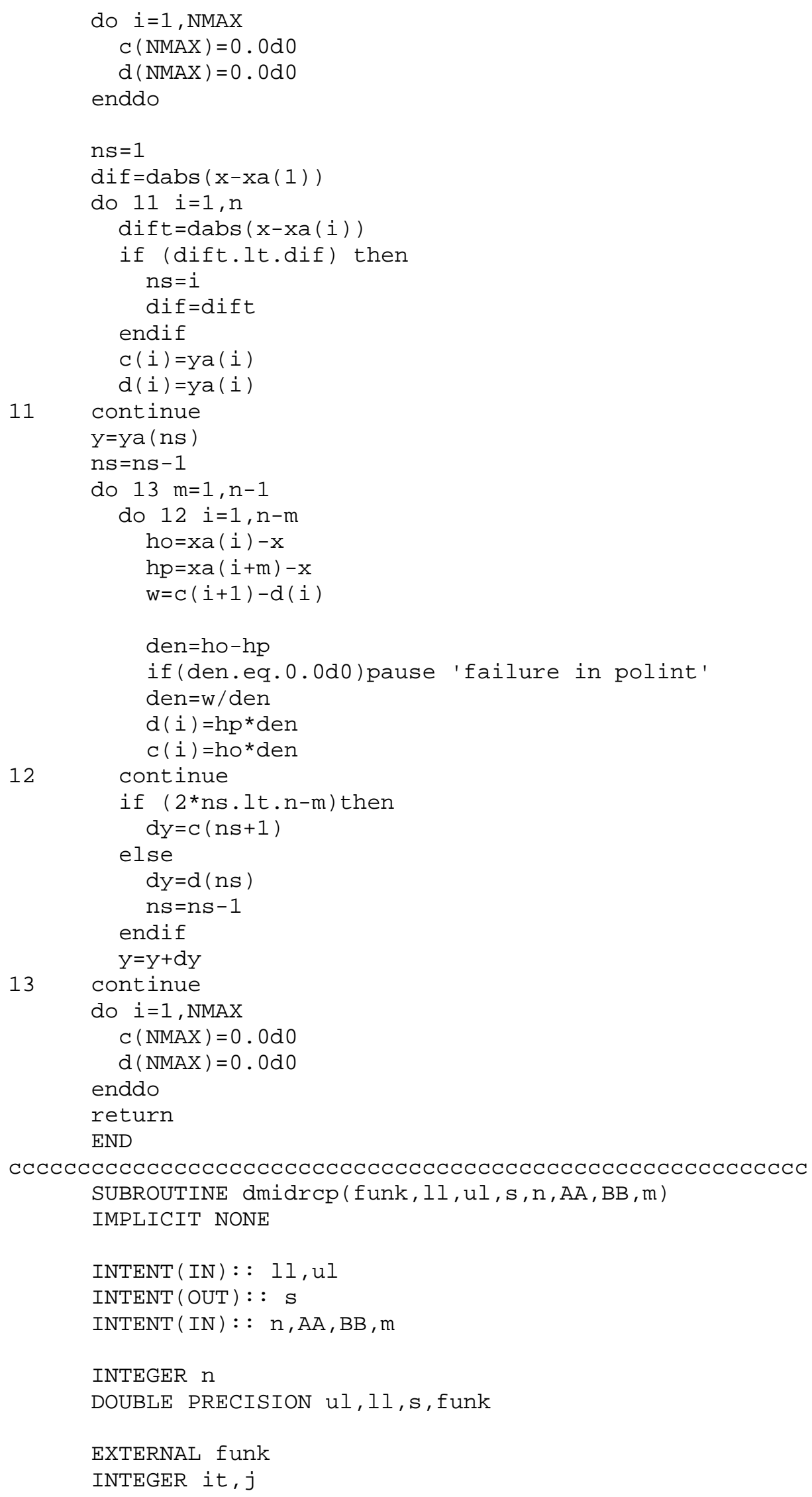


C

DOUBLE PRECISION ddel, del, sum, tnm, $x$, func $, a, b, c, d$ DOUBLE PRECISION dum DOUBLE PRECISION $A A, B B, m$ PARAMETER $(c=1.0 \mathrm{~d}+\odot, \mathrm{d}=5.0 \mathrm{~d}-2)$ $x \rightarrow 1 /(1+C X) * * d$ func $(A A, B B, m, x)$ $\&=\operatorname{funk}\left(A A, B B, m,\left(1.0 d \Theta /\left(x^{* *}(1 . \Theta d \theta / d)\right)-1 . \Theta d \theta\right) / c\right)$ $\& /\left(c^{*} d^{*} x^{* *}(1.0 d \Theta / d+1.0 d \Theta)\right)$

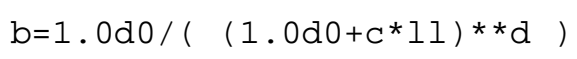




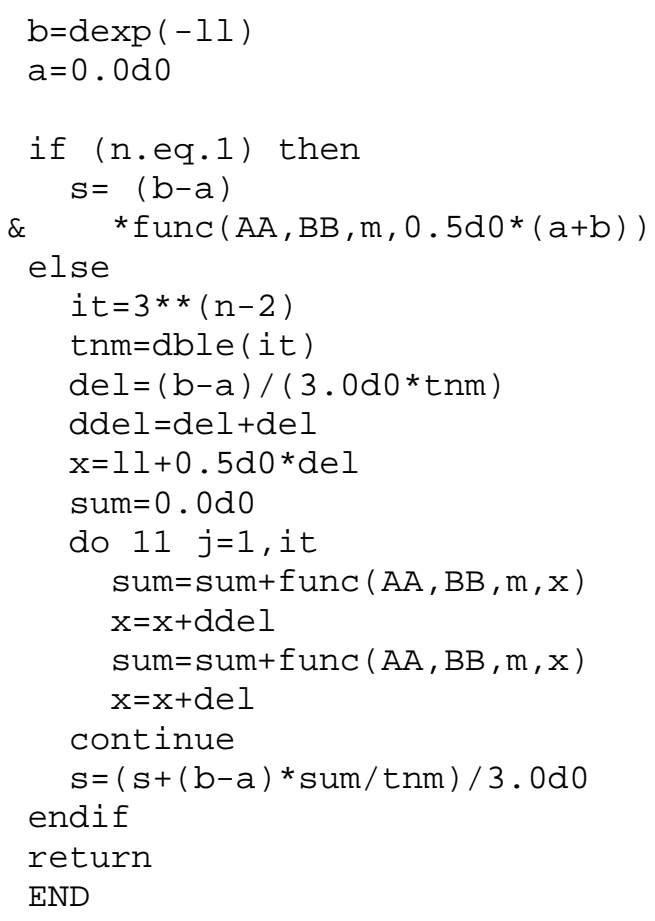

\section{Fortran function FUNCT}

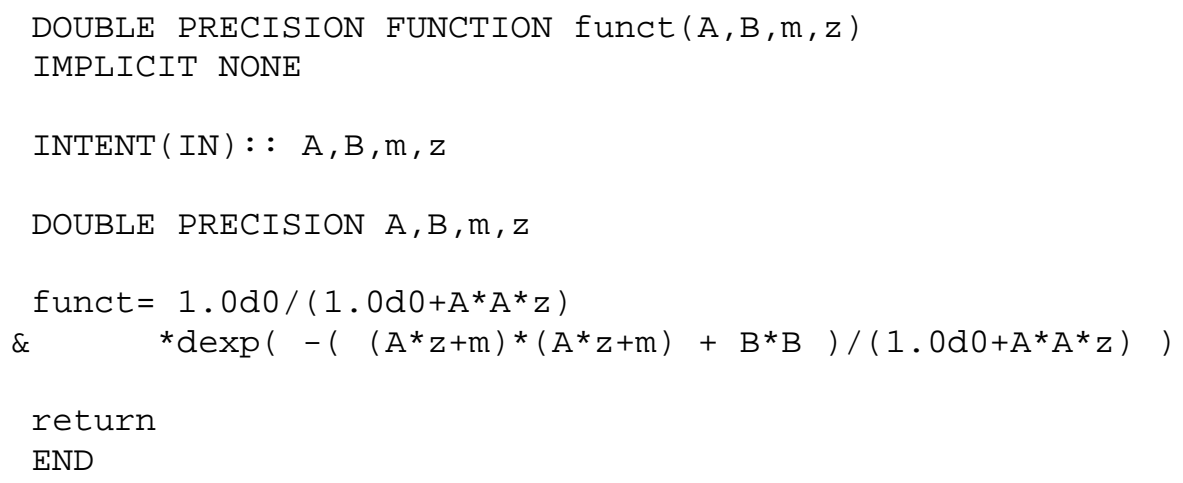

\section{Fortran input file INPUT.DAT}

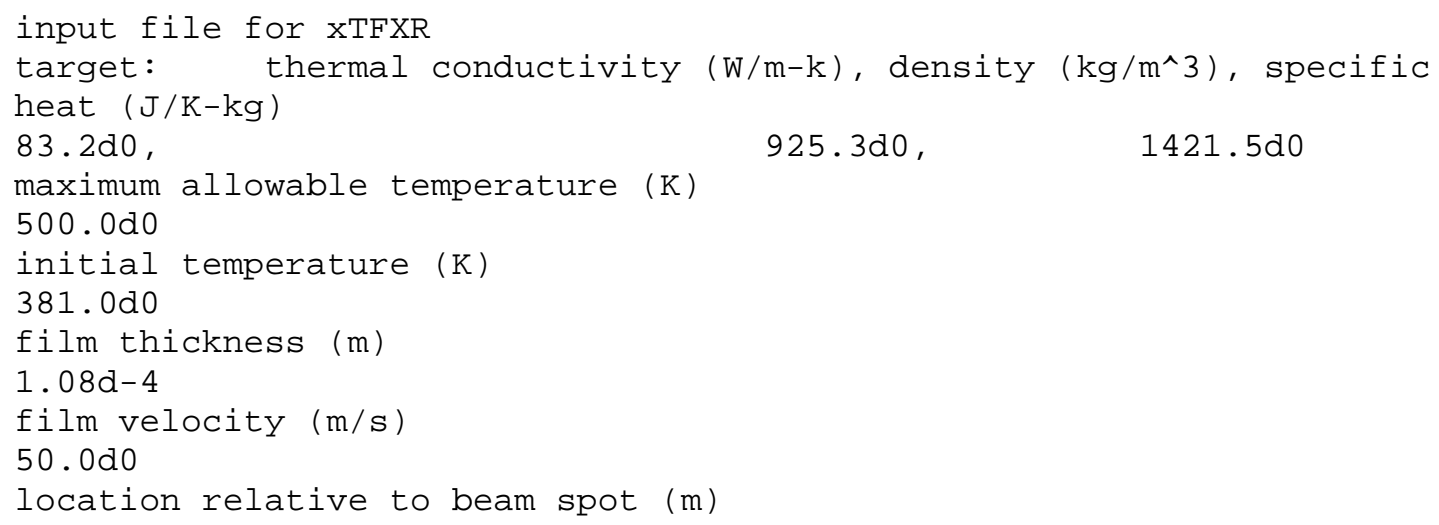


ANL-06/10

$\odot . \odot d \odot$

beam power (W)

1902 . odo

beam spot radius $(\mathrm{m})$

$0.5 d-3$

area of calculation $\mathrm{H}, \mathrm{W}(\mathrm{m})$

30. $0 \mathrm{~d}-3, \quad$ 10.0d-3

number of grid $\mathrm{H}, \mathrm{W}(-)$

$50, \quad 50$ 


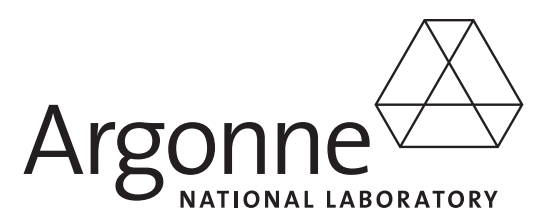

Nuclear Engineering Division / Physics Division

Argonne National Laboratory

9700 South Cass Avenue, Bldg. 208

Argonne, IL 60439-4842

www.anl.gov

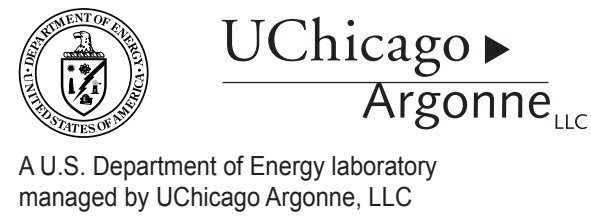

